\title{
Sex and Gender Related Health Status Differences in Ancient and Contemporary Skeletal Populations
}

\author{
Velissaria Vanna \\ UCL Institute of Archaeology
}

\begin{abstract}
Human skeletal and dental remains are an invaluable source of information for interpreting the way of life of past people and also provide the only direct evidence of non-living populations' health status. This research paper discusses the sex-related health differences observed in two skeletal populations from Greece, an ancient and a modern, by employing multiple health indicators, and aims at determining the biological and possible social factors that contribute to this variation. Particular emphasis is given to the importance of hypotheses-driven, population-based studies of human remains as the most effective means of reconstructing life in the past. The results showed that fracture (ancient: females $0.08 \%$, males $0.12 \%$; modern: females $0.38 \%$, males $0.19 \%$ ) and osteoarthritis (ancient: females $0.7 \%$, males: $3.0 \%$; modern: females $4.4 \%$, males $3.2 \%$ ) frequencies were higher for male individuals than females in the ancient population, which can be explained by greater engagement in strenuous and risky activity. Dental caries (ancient: females $1.2 \%$, males $1.8 \%$; modern: females $23.6 \%$, males $17.4 \%$ ) and ante-mortem tooth loss (ancient: females 12.3\%, males 7.7\%; modern: females $69.5 \%$, males $49.5 \%$ ) rates were higher for females than males (with the exception of the almost equal caries rates for the ancient population), most likely due to hormonal fluctuations, saliva content and flow, because female teeth erupt earlier and also perhaps as a result of differences in dietary habits. Periodontitis levels were more elevated in males (ancient: females $9.6 \%$, males $30.1 \%$; modern: females $29.1 \%$, males $38.3 \%$ ), possibly due to poor oral hygiene practices and excessive masticatory loading. Dental enamel defects rates showed that in the ancient population, males had more chances of surviving childhood stress than females (females $19.5 \%$, males $20.0 \%$ ), whereas, in the modern population, the exact opposite was the case (females $6.1 \%$, males $22.7 \%$ ).
\end{abstract}

\section{Keywords}

Ancient and modern skeletal populations, contemporary Athens, health status, Hellenistic Demetrias, palaeopathology, sex and gender differences

\section{Introduction}

In this paper, an important but also complicated area of research is discussed: the sex-related health status differences as revealed by human skeletal remains and more particularly, palaeopathology. Since palaeopathology as a science depends on the development of methodologies based on comparative methods (Armelagos 1998: 3), a comparative method is used here to test hypotheses of sex differences in health status as a result of biological and social factors.

The main aims of this paper are to:

- $\quad$ Identify the health differences between the sexes.

- Examine the influence of sex (biologically-determined) and gender (socially-determined) on the prevalence, distribution and pattern of disease in skeletal populations.

- Investigate the importance of the use of multiple health indicators and hypotheses-testing, population-based studies in bioarchaeology.

Papers from the Institute of Archaeology 18 (2007): 114-147 
In order to achieve these goals, 200 adult individuals, 100 from an ancient $\left(3^{\text {rd }}-1^{\text {st }}\right.$ century $\mathrm{BC}$ ) and 100 from a modern (late $19^{\text {th }}$-late $20^{\text {th }}$ century AD) population (Eliopoulos et al. 2007) in Greece were examined macroscopically. Certain dental and skeletal pathological conditions (discussed below, in the Methodology section) were recorded and a statistical analysis was carried out in order to estimate the prevalence of the diseases in the two populations under study and to observe their distribution and pattern within them. It should be noted however, that the results presented here are preliminary, as they are based on the study of a part of the populations.

The present research provides the rare opportunity to study sex-related health differences in both an ancient and a modern skeletal population and to observe how sex and gender affects the prevalence and pattern of disease in skeletal populations with totally different backgrounds in terms of sources of energy, occupation, activity, labour division, technology, mechanisation, population density, environmental conditions, physical environment, exposure to pathogens, access to medical treatment, medical development, diet, cultural and social conditions, among others. Comparing the (between the sexes) distribution of pathology between populations with major differences in all of the above factors, assists us in determining whether it is the social or the biological conditions that mostly affect the disease prevalence differences between male and female individuals.

The general hypothesis is that, since the social and environmental conditions are totally different between the populations under study, it is expected that this will be reflected in the results of the present study. More specifically, it is expected that the distribution of pathology between the sexes will not be the same in both populations. If the opposite is the case, it is assumed that this will probably mean that the sex-differences in prevalence should be attributed to biological factors that remain constant in both populations.

\section{Hypotheses Established and the Rationale Behind Them}

Sex and gender are concepts wrought with confusion; it is therefore necessary to define these terms and to make a distinction between them. Sex is defined by the biological differences between males and females determined at the moment of conception and enhanced in subsequent physiological development. Gender is the cultural construct in which individuals are socially classified into categories such as male and female (Armelagos 1998: 1).

Both terms are used in the current study, because the factors resulting in the health differences between males and females and affecting the prevalence, distribution and skeletal/dental pattern in an osteological population, are both biological and social, i.e. both sex- and gender-related. These factors formed the basis for establishing the hypotheses below.

The biological factors include: (a) the enhanced female immune reactivity (Ortner 1998), (b) the hormonal fluctuations in women during puberty, pregnancy, menses and 
menopause (Lukacs and Largaespada 2006) (c) the increased mortality of women in the child-bearing years (Armelagos 1998), (d) the lower mortality rate of women early in life and in the later years (Roberts et al. 1998; Stini 1990), (e) the greater muscle power in men (Relethford 2006), (f) the earlier eruption of teeth in women (Hillson 1996; Lukacs and Largaespada 2006) and (g) the lower quality and quantity of saliva in women (Lukacs and Largaespada 2006).

The social factors that result in sex-related health differences may vary according to the society that the population under study once represented. The Hellenistic Age was a period of large-scale political and social upheaval and in general there was an erosion of the asymmetry between the sexes and a consequent improvement in the status of women. We know a few instances of women being awarded honorary citizenship or even magistracies, owning land and slaves, being wealthy, even migrating. Increased opportunities for education contributed to the emergence of women poets, artists, and philosophers. Independence of action in public was a fact for some women who also apparently lived in households without men in some cases (Fantham et al. 1994). However, the extent to which these changes affected everyday lives of women and men should not be exaggerated (Blundell 1995: 200). Women were still considered to be inferior to men and continued to spend most of their time in the house. Even if the masculine and feminine spheres may have been less sharply differentiated in the Hellenistic period compared with the Classical, the gender gap had by no means been eradicated, and this remains the case for women of $20^{\text {th }}$ century Athens. There are certainly signs of gradual social transformation; women were seen to play more prominent roles in public life, especially during the last two decades of the $20^{\text {th }}$ century (Clogg 2002), but most of them were still housewives, secluded in their houses, and still in the process of fighting for equality between the sexes. The written records found in the modern cemetery confirm that $82.7 \%$ of adult women of known occupation were housewives (Eliopoulos 2006). Finally, even in modern Greece, especially in the rural areas, there is a cultural preference for male children, which may result in less favourable treatment of girls. Numerous factors could be involved, including nursing practices and inequality in access to suitable food and medical resources (King et al. 2005: 556).

One can argue that that sex differences in social and biological status, i.e. diet/nutrition and health, are a human universal. Therefore, the socially-related factors affecting the health differences associated with the sexes still remain: (a) the differential access to the quality and quantity of food: women tend to be undernourished and usually rely on cheaper foodstuffs, such as carbohydrates, whereas men tend to consume more meat (Cook and Hunt 1998; Grivetti 2001); (b) the seclusion of women in the house (Fantham et al. 1994); (c) the different types of occupation and general activity: men tend to get involved in more strenuous and risky jobs and activities (Standen and Arriaza 2000); (d) less favourable treatment of female children (King et al. 2005).

The important question is what effect all these factors may have had on the distribution between the sexes of the diseases used in this study as health indicators. 
Hypothesis 1: Male individuals are expected to exhibit higher overall frequencies of osteoarthritis and trauma because they tend to get involved in more physically demanding and risky jobs than women (Standen and Arriaza 2000). In the older adult groups in the modern population however, osteoarthritis and pathological fractures should arguably be more common in females, again because women live longer and are predisposed to osteoporosis, which causes pathological fractures, more frequently than men (Brickley 2002; Mays et al. 2006; Stini 1990).

Hypothesis 2: The levels of caries in the modern population are expected to be higher in the females. Women tend to be affected more by the disease for several reasons discussed below. In the ancient population, the difference between males and females is expected to be smaller, mainly because ancient populations, whose diet did not include sugar, were not affected by caries in as young an age as in modern populations, and we also do not know whether women lived longer. The same should be the case for periodontal disease and ante-mortem tooth loss. It is also possible that higher periodontitis rates in females are the result of hormonal fluctuations (Hillson 1996).

Hypothesis 3: For dental enamel defects, it is almost impossible to establish a hypothesis. Women are more buffered against the effects of the environment, as their immune response is more effective on average than that of males, and their prognosis for recovery is more favourable; males have a higher mortality rate in most countries in the first few weeks and months of life (Roberts et al. 1998: 94). So, one may assume that women should exhibit lower rates of dental enamel defects. However, the absence of a lesion may indicate that the person did not suffer any infection, that the person suffered from an infection but recovered quickly (so that there was no time for the disease to leave a mark on the teeth or bones), or that the individual was too frail to resist the disease and died immediately or soon after (Wood et al. 1992). Therefore, the assumption that the female individuals should exhibit higher rates of enamel defects because most of them would have survived the infection when they were children, whereas more male children would have died immediately, could also apply.

\section{Methodology}

Human bones and teeth preserve the greatest amount of biologically relevant information about the past. However, the enormous potential of the study of human remains has only relatively recently become realised (Hooton 1930; Wells 1964). This is the case mainly because most human osteological analysis has been descriptive and oriented around case studies (Ivanhoe 1970; Stewart 1958). Even for large assemblages of skeletons, osteological reports tended to overlook pattern and tendency in a population perspective (Angel 1981; Larsen 1997). The current research is based on the population approach because it is critical for characterising patterns of human behaviour and lifestyle.

It also poses questions by comparing datasets from skeletal assemblages representing human populations (subgroups within the same population) from different levels of biological and social complexity, by using the multiple health-indicator approach, which 
"stems from the recognition that health is a composite of nutrition, disease and other aspects of life history" (Larsen 1997: 8). The indicators that were used to explore the health of people and to compare the two sexes were: osteoarthritis, fractures and dental pathology and wear. The prevalence, the distribution in the population and the pattern in the skeleton of these diseases can provide information on the lifestyle, activity, diet and biological status of a population or a subgroup within it.

Osteoarthritis is a multifactorial disorder (Hoffman 1993; Rogers and Waldron 1995) and aetiological factors include: trauma, activity, age, age of onset, genetic predisposition, other arthropathies, sex, obesity and diet, etc. (Jurmain 1999). The condition has been intensely used to reconstruct behaviour in past populations and very often associated with activity and occupation. This approach has been criticised (Bridges 1992, 1993; Jurmain 1991; Weiss and Jermaine 2007) and there also have been many studies that found negative correlations of activity with the development of the condition (Lawrence 1955; Moskowitz 1993). Others however, have shown that there is a strong relationship between activity and the presence of osteoarthritis (Felson et al. 1991; Kujala et al. 1995; Lawrence et al. 1966; Lawrence 1969; Stenlund 1993; Vingard et al. 1991) and it is believed that, although osteoarthritis should not be used to infer specific activities (Jurmain 1999: 105), on a population basis, it is permissible to make some inferences about activity generally (Rogers and Waldron 1995: 107). Sex comparisons, both in Greece and elsewhere, have also revealed significant differences between males and females, which are suggestive of contrasting patterns of physical activity (Bourbou 2004; Bridges 1991; Derevenski 2000; Fahlstrom 1981; Larsen 1982; Lezzi 2005; Triantafyllou 2001). In the present study, osteoarthritis was employed to offer insight into behavioural characteristics of the populations under study and into labour division and to test Hypothesis 1.

Fractures are common pathological lesions that are relatively easily observed in human skeletal assemblages and "represent the accumulation of physically traumatic events in an individual's life that resulted in broken bones" (Judd and Roberts 1999: 229-230). The assessment of such injuries can provide information on a population's relationship with their physical and cultural environment and their exposure to risk (Alvrus 1999; Domett and Tayles 2006; Grauer and Roberts 1996; Judd and Roberts 1998; Kelley and Angel 1987; Lovejoy and Heiple 1981). Several studies suggest that sex affects the distribution of fractures in a population and have shown significant differences in their prevalence between males and females (Judd 2004; Judd and Roberts 1999; Standen and Arriaza 2000). In this paper, and on the basis that accidental injuries reflect the hazards of day-to-day living, fractures were used in order to investigate differences in the lifestyle between the sexes and to test Hypothesis 1.

Dental caries is a disease process associated with factors such as exposure of teeth surfaces to the environment, the presence of oral bacteria flora, diet and influenced by tooth morphology, enamel defects, attrition, oral and plaque $\mathrm{pH}$, heredity, hormonal fluctuations, salivary composition and flow, nutrition, periodontal disease, etc. (Hillson 1996; Hillson 2000; Larsen 1997; Lukacs 1989; Lukacs and Largaespada 2006). However the role of diet is undoubtedly one of the most important factors affecting 
the prevalence and distribution of carious lesions within and between populations and therefore, the study of this dental disease may yield valuable clues regarding diet and nutrition. Research has recognised a positive association between high rates of caries and carbohydrate consumption and differences in the prevalence of the condition between the sexes, with females being more affected in most cases (Behrend 1978; Hillson 1979; Larsen 1983; Seidel 1995).

Among the reasons for the higher female rate of caries are hormonal fluctuations (Lukacs and Largaespada 2006). A growing body of research reveals that caries rates increase proportionally with increasing oestrogen levels (Liu and Lin 1973; Legler and Menaker 1980; Shafer and Muhler 1954), which are higher in females throughout the life cycle and significantly higher during puberty, pregnancy and menstruation (Angsusingha et al. 1974; Niswender et al. 1976; Worthman 1995). Fluctuation in the level of oestrogen influences thyroid activity and leads to reduction of saliva flow rate (Muhler and Schafer 1955), which impacts on oral health (Tenovuo 1997, 1998). In fact, anything that compromises saliva flow is expected to have a negative impact on oral health (Tenovuo 1997), including malnutrition (Lingstrom and Moynihan 2003). Research on the salivary flow rate has revealed that females have a significantly lower mean saliva flow rate than men (Percival et al. 1994). Vadiakas and Lianos also examined the correlation between caries and pregnancy and noted that there are four factors that appear to be highly significant during pregnancy: changes in mouth flora and

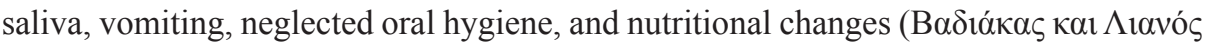
1988). Another factor affecting caries rates is the fact that females' teeth erupt earlier than the males' and are therefore exposed to it for longer early on in life (Hillson 1996, 2000; Larsen 1997).

Another dental disease associated with diet, oral hygiene practices, bacteria flora among other factors is periodontal disease, and subsequent antemortem tooth loss. Sex differences in periodontitis prevalence are not consistent and not as pronounced as in caries but, most of the times, males seem to be more affected than females (Hillson 1986; Lukacs 1992). Dental caries, periodontal disease, antemortem tooth loss were used to test Hypothesis 2 and to investigate the issue of sex differences in diet, differential access to food resources, nutrition and dietary habits.

Dental defects of enamel are the result of three potential causes, including hereditary anomalies, localised trauma and systemic metabolic stress (Goodman and Rose 1991). Defects arising as hereditary anomalies or as localised trauma are rare in human populations (Larsen 1997: 45), indicating that the vast majority seen in skeletal populations are linked to systemic physiological stress (Bowman 1991; Goodman and Rose 1990; Kreshover 1960; Pindborg 1982; Suckling et al. 1983, 1986). Several different issues related to dental enamel defects have been addressed over the past decades, including comparisons between the sexes and have indicated significant differences in the prevalence of the defects between males and females (King et al. 2005; Lovell and Whyte 1999; Palubeckaite et al. 2002; Slaus 2000). In the present study, dental defects of enamel were employed because they provide an excellent source of information towards reconstructing a retrospective stress and morbidity history of human populations, 
past or present. It was thus expected to provide insight into the issue of favourable treatment of male children and to test Hypothesis 3.

\section{Recording System}

Sexing and Ageing

The presence/absence of teeth, bone elements and joint surfaces and their state of preservation were recorded, and the sex and age of each individual was estimated, using standard methods:

Sexing:

- Os coxae morphology scoring system (Phenice 1969).

- Cranial morphology scoring system (Acsadi and Nemeskeri 1970).

- Metric characteristics (Bass 1995).

Ageing:

- Suchey-Brooks pubic symphysis morphology scoring system (Brooks and Suchey 1990; Suchey and Katz 1986).

- Auricular surface morphology scoring system (Lovejoy et al. 1985; Meidl and Lovejoy 1985).

- Cranial suture closure scoring technique (Meidl and Lovejoy 1985).

- Sternal end of ribs (Iscan et al. 1984, 1985).

- Final stages of skeletal maturation (iliac crest, medial clavicle, etc.).

- Dental attrition (Brothwell 1981; Miles 1962) (for the ancient population only because the methods have been tested on earlier populations, in which occlusal attrition was much heavier than in contemporary populations).

Age at death can be estimated by observing the state of one or more morphological indicators that tend to fall within a chronological age range, although individuals of the same chronological age can show different degrees of development (Chamberlain 2000). For this reason, although the age of the individuals from the modern collection was known, it was assessed following the standard procedure used for the ancient collection and the results of the age assessment were used, rather than the actual age, for comparing among age groups and between populations. As with ageing, the sex of the modern collection was determined employing the same methods used for sexing the individuals from the ancient population and the results of the sex assessment were used rather than the actual sex.

\section{Pathology}

The skeletons were then examined macroscopically, and the following conditions were recorded as being present or absent in each bone, joint surface or tooth: osteoarthritis (Rogers and Waldron 1995), fractures (Lovell 1997), occlusal attrition (Smith 1984), periodontal disease (Karn et al. 1984; Kerr 1991), antemortem tooth loss and dental enamel defects and caries (Hillson 2001). It should be noted that the frequencies of osteoarthritis, fractures and, dental pathology and attrition were calculated by dividing the pathological bones (or bone parts), joint surfaces or teeth by the bones, joint surfaces or teeth present in the skeletal samples. 
Statistical Analysis

Statistical analysis was carried out using the SPSS 11.0 statistical package. ANOVA (analysis of variance, a parametric test) was used to determine statistically significant variations in the presence of trauma and joint disease between the sexes and among the age groups. Tests of Normality (Kolmogorov-Smirnov and Shapiro-Wilk) were carried out and showed that some of the data violated the basic assumptions of the normal distribution that underlie parametric tests (Salkind 2000: 264), or that some of the samples were too small (i.e. less than 30). In such cases, and when ANOVA did not indicate a statistically significant difference, the Kruskal-Wallis non-parametric test was employed. Homogeneity of Variance Test and Post Hoc (Games-Howell for $<0.05$ and Tukey for $>0.05$ ) were applied for testing significance levels among age groups, in order to check in which age group the difference was. The significance level chosen was $0.05(95 \%$ confidence level). Differences were considered highly significant when Sig. or Asymp. Sig. $<0.01$.

For dental pathology and attrition, chi-square tests were used to determine statistically significant variations in the presence of caries, periodontitis, enamel hypoplasia and occlusal attrition, between the sexes and among age groups. Fisher's exact tests were employed when the sample sizes were small (Zar 1999). A critical level of acceptance or rejection was established at $5 \%$ and differences were highly significant at $1 \%$.

\section{Material and Sites}

\section{Hellenistic Demetrias}

The Hellenistic town of Demetrias was founded by the Macedonian king Demetrios Poliorketes between 294 and 292 BC by merging many smaller towns of Magnesia, a region (now part of Thessaly) in central eastern Greece, with the purpose of creating

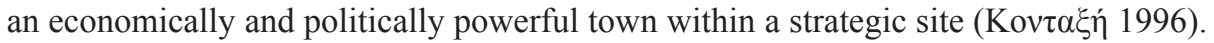
Archaeological evidence reveals a flourishing industrial and commercial city with a mixed population of Macedonians, Greeks from the mainland, the islands, and Sicily, and immigrants from Asia Minor, Egypt, Syria, and Phoenicia (Vanna 2005: 115).

\section{The Ancient Collection}

The skeletal material under study comes from the 924 burials of the North Cemetery of the Hellenistic town of Demetrias. These were situated outside the walls, and they were excavated in the years 1995 and 1996 by the $13^{\text {th }}$ Ephorate of Classical and Prehistoric Antiquities of Volos, under the direction of E. Nikolaou. Approximately 350400 skeletons comprise the collection, which dates from the $3^{\text {rd }}$ to the $1^{\text {st }}$ century BC. Unfortunately, there is no sex and age distribution of the total individuals from the site, because this is the first study of this particular assemblage. Table 1 shows the sex and age distribution of the sample studied so far.

One hundred of the skeletons from the collection have been studied so far. These skeletons come from the 150 burials that contained grave-goods. This selection was made because, at the time that the sample was taken from the Ephorate of Volos to the Laboratory in Athens, these were the only burials that were dated with accuracy and could be subdivided into at least two distinct chronological periods (Early and Late Hellenistic). 
Therefore, if the fact that some of the burials of the Demetrias cemetery contained grave goods and others did not is associated with the social status of the individuals, then the sample studied so far, may not be representative of the population of the town as a whole; however, when the rest of the skeletons are studied, this problem will be eliminated. The sample of 100 skeletons that has been studied so far was randomly drawn from the 150 burials (some of them contained more than one individual) with grave goods.

\begin{tabular}{|l|l|c|c|c|c|}
\hline \multicolumn{2}{|c|}{} & \multicolumn{3}{|c|}{ AGE } & \\
\hline \multirow{2}{*}{ FEX } & POPULATION & Younger & Middle & Older & Total \\
\hline \multirow{2}{*}{ Female } & Demetrias & 15 & 10 & 12 & 37 \\
\cline { 2 - 6 } & Athens & 7 & 15 & 21 & 43 \\
\hline \multirow{2}{*}{ Male } & Demetrias & 13 & 27 & 18 & 58 \\
\cline { 2 - 6 } & Athens & 20 & 12 & 24 & 56 \\
\hline \multicolumn{2}{|l}{ Total } & 55 & 64 & 75 & 194 \\
\hline
\end{tabular}

Table 1. Sex and age distribution in Demetrias and Athens.

The criteria for selecting this site and this skeletal collection were as follows:

- Good preservation of the skeletons.

- Adequate amount of skeletal remains.

- Availability of excavation records and mortuary evidence.

- Time-period; little is known about the Hellenistic period.

- Geographical location; no anthropological work has been carried out here before.

- Historical and archaeological importance of the site.

\section{$20^{\text {th }}$ Century Athens}

Athens as the capital of Greece since 1834 was the centre of political, economic and cultural developments. The $20^{\text {th }}$ century was a period of constantly changing socioeconomic conditions, mainly affected by the Ottoman sovereignty, which started in AD 1453 and ended in 1832, when the first Greek government was formed, but in some parts of Greece lasted until 1947, the Balkan Wars (1912-1913), the two World Wars (and 1914-1918 and 1939-1945), dictatorships (1936-1939 and 1967-1974), a civil war after World War II, political interference of great powers, population exchange, and so on. Athens experienced a major growth of urbanisation, especially in the second half of the $20^{\text {th }}$ century, the decades after World War II (from the 50's until now) which also witnessed an acceleration of contact of all kinds with other European countries in areas such as trade, travel, diplomacy and exchange of ideas (Vanna 2005: 115).

\section{The Modern Collection}

The modern collection consists of 225 individuals from two contemporary cemeteries in Athens. It is unique in Greece, and is considered to be representative of the population of Greece as the individuals of the sample came from many different parts of the country and from various socio-economic backgrounds; both sexes and age groups 
are represented too. The people buried in the two cemeteries died in Athens between 1960 and 1996 and their dates of birth range from the late $19^{\text {th }}$ to the late $20^{\text {th }}$ century. In Greece, the deceased are exhumed three years after the date of their burial and their bones are placed into boxes where they remain until the family of the deceased decide that they no longer want them in the ossuary. The bones are thereafter disposed of in large pits within the cemetery. The skeletons of the modern collection were obtained by the Laboratory of Biological Anthropology, Department of Biology, University of Athens, where the collection is curated, before this last stage of their disposal into the pits, while they were still in the ossuary. There are written records of age, sex, occupation, place of birth, cause and year of death for each individual. All the skeletons are in an excellent condition and all the bones are complete. The data for sexing, ageing and skeletal and dental pathology for one hundred skeletons, that have been randomly selected, were collected until November 2005. Table 1 shows the sex and age distribution of the individuals studied so far.

The criteria for selecting this collection were:

- The fact that this is the only modern assemblage available in Greece at the moment.

- The excellent preservation of the skeletons.

- The adequate amount of individuals.

- The availability of written records of sex, age, etc.

- Its comparability with the archaeological collection; both come from urban commercial and political centres and ports, which are cosmopolitan with mixed populations.

\section{Results and Discussion \\ Trauma}

In the ancient population males are generally more frequently affected by fractures than females (Table $2 \mathrm{a}, \chi^{2}=1.929, \mathrm{df}=1$, Asymp. Sig. $=0.165$ ), thus confirming Hypothesis 1 based on the fact that men are involved in riskier activities than women and spend much more time outside the house. One type of activity-induced trauma is spondylolysis (Fig. 1) that was found in higher frequencies in male individuals (Merbs 1996, $2001,2002 \mathrm{a}, 2002 \mathrm{~b})$. In the modern population, the males seem to be less frequently affected than females $\left(\chi^{2}=1.621, \mathrm{df}=1\right.$, Asymp. Sig. $\left.=0.203\right)$ but this is misleading; the overall percentages are higher for females simply because there is a high frequency of vertebral crush fractures, possibly secondary to pathology, i.e. osteoporosis, in the older ages (Table 2b) and because females live longer (Fig. 2). In fact, in the younger (20-35 yrs) and middle-age (35-50 yrs) groups, males sustain more fracture frequencies than females, again confirming Hypothesis 1.

The pattern of skeletal involvement is quite different when comparing the sexes. In both populations, the most common site of trauma for females is the vertebral column. The most frequently affected bone group for males from the ancient population are the ribs, followed by the long bones and then the vertebrae, and for males from the modern population, the clavicles and scapulae, followed by the vertebrae and then the long bones 


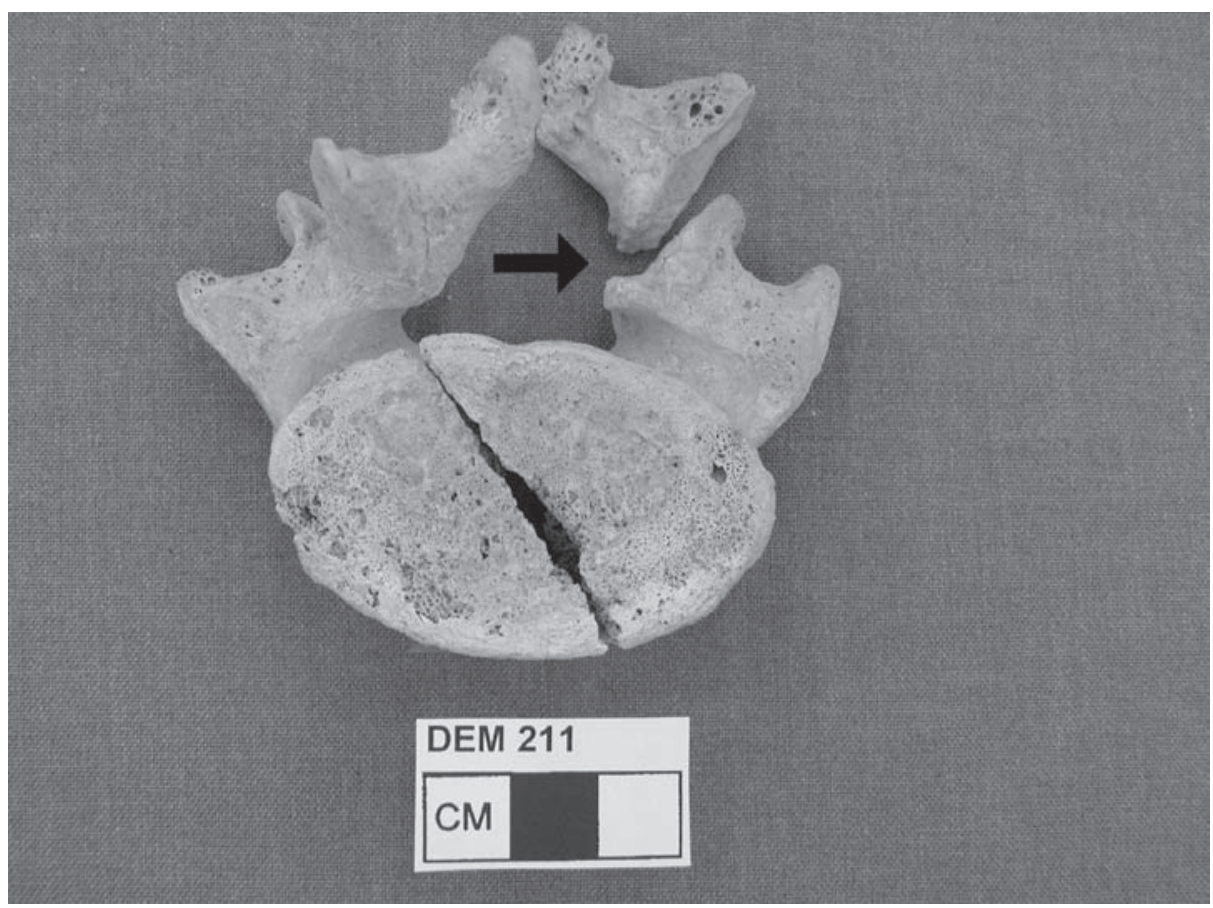

Figure 1. Unilateral spondylolysis (fracture in the neural arch) related to activityinduced trauma (example from the ancient collection).

\begin{tabular}{|l|l|c|c|c|}
\hline POPULATION & SEX & Bone Segments (N) & Fractures (n) & Fractures (\%) \\
\hline \multirow{2}{*}{ Demetrias } & Female & 2649 & 2 & 0.08 \\
\cline { 2 - 5 } & Male & 4992 & 6 & 0.12 \\
\hline \multirow{2}{*}{ Athens } & Female & 11710 & 44 & 0.38 \\
\cline { 2 - 5 } & Male & 15548 & 30 & 0.19 \\
\hline
\end{tabular}

Table 2a. Frequencies of fractures by sex.

In all the groups of bones with fractures, the males show higher rates than females, except in the case of the vertebrae, probably because women tend to suffer more from vertebral crush fractures secondary to osteoporosis (Brickley 2002; Mays et al. 2006); and this is the case for both populations under study. In the modern collection, the fact that the clavicles and the scapulae are the most common site of involvement is due to multiple healed fractures caused by motor-vehicle accidents, which are very common in the contemporary population and a major cause of death, especially in the younger ages (Eliopoulos 2006). This pattern is also observed in peri-mortem (around the time of death/not healed) fractures: the pelvis, the clavicles and the scapulae are the most commonly fractured bones in this particular population sample. It seems that the fractures in the pelvis were lethal, and this is the reason why there are no ante-mortem 


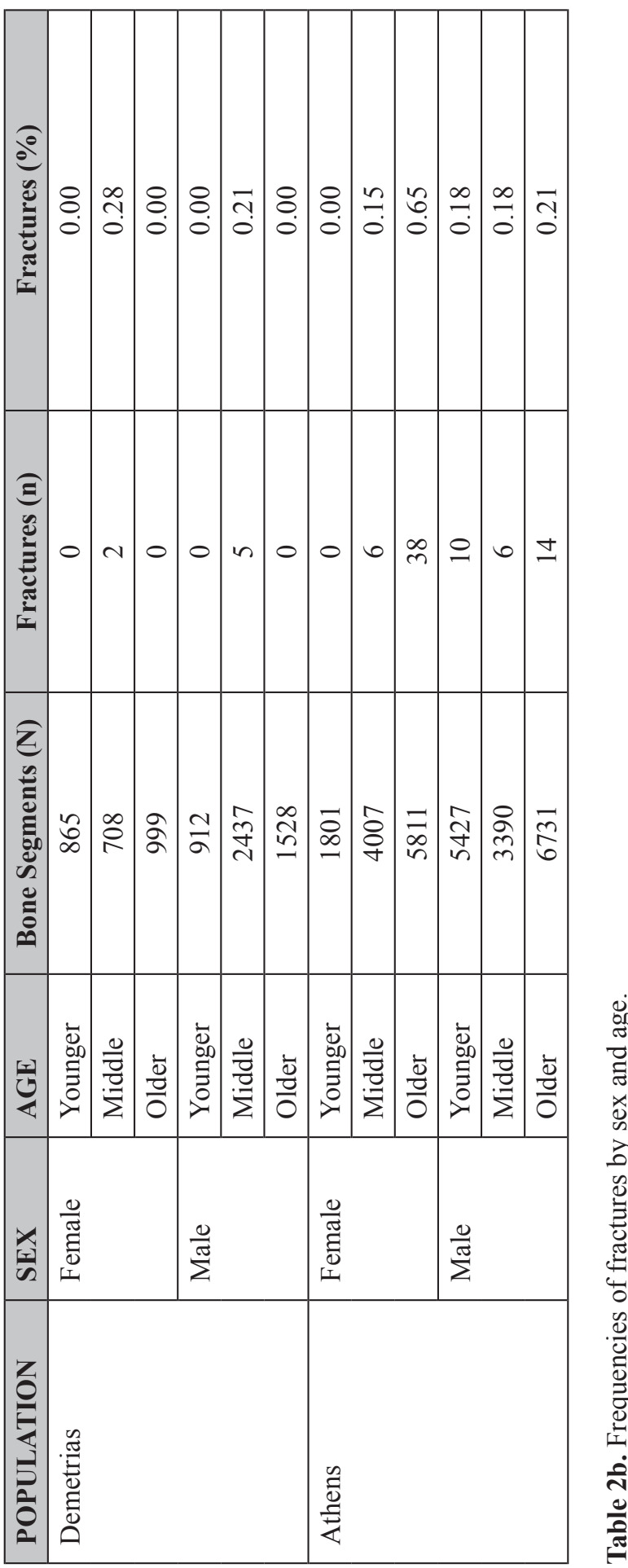


(before death/healed) fractures in the pelvic girdle, whereas other accidents involving the clavicles and scapulae had not always been lethal and the individuals survived the injuries. It is therefore confirmed that men in both populations were involved in more hazardous activity than women.

\section{Osteoarthritis}

In the ancient population, osteoarthritis, both in the spine and the rest of the joints, is more frequent in males (Tables $3 \mathrm{a}$ and 3c, $\mathrm{F}=112.519$, df $=1$, Asymp. Sig. $=0.261$ ), who are more likely to have had a heavy workload than females. In the modern collection, on the other hand, the frequency is higher in the female individuals (Tables $3 \mathrm{a}$ and $3 \mathrm{c}, \mathrm{F}=0.348, \mathrm{df}=1$, Asymp. Sig. $=0.561$ ), which is what was expected, since, firstly, females are generally more predisposed to osteoarthritis than males (Hanna et al. 2005; Richette et al. 2003; Wluka et al. 2001) and secondly, because they have a greater lifespan and are therefore exposed to the condition for longer. So, in the ancient population, the social factor prevails against the biological: men tend to undertake more physically-demanding tasks (Standen and Arriaza 2000), whereas women are more predisposed to osteoarthritis: in the contemporary population, the biological factor is stronger than the social. This is also associated with the fact that in the ancient collection, the average age-at-death is higher for males, whereas in the modern collection the exact opposite is the case (Fig. 2).

Although in the modern group the overall (regardless of age) rates of osteoarthritis are higher for females, the overall (regardless of age) frequencies of the disease in the major joints (knee, hip (Fig. 3), elbow and shoulder together) are higher for male individuals, which means that women are more affected in the smaller joints, such as those of the hands and feet. Comparing each subgroup of bones separately, in all the major joints, except for the knee joint, the overall (regardless of age) osteoarthritis frequencies were higher in the male individuals. In the knee joint, in the middle adult group (35-50 yrs), the males are more often affected, whereas there are no females with osteoarthritis in this age group. The condition seems to develop after the age of 50 in women, who, after this age, are affected three times more than men (Table $3 \mathrm{~b}$ ). This is possibly due to the fact that they are predisposed to the condition after a certain age (Hanna et al. 2005; Richette et al. 2003), and also because they live longer. This means that the disease in women is more closely associated with age and high oestrogen levels than activity, whereas in males, it is more strongly related to activity and that is the reason it appears in a much younger age ( 35 years) in men.

The frequency of vertebral osteoarthritis was found to significantly increase with age in both sexes and samples (Table 3d). In the ancient population, in the female group, only the older adults are affected, whereas in the male group, a relatively high percentage of the vertebrae of younger individuals (20-35 yrs) were recorded as being pathological. After the age of 50 years, the males are five times as much affected by osteoarthritis of the spine as females. In the modern collection, vertebral osteoarthritis is more prevalent in females. Two findings support the widely accepted view that the condition is very strongly associated with activity: the fact that in the ancient population, where men lived longer than women, the frequency of vertebral osteoarthritis is much higher in male individuals and that in the modern population, in which women lived longer than men, the rates are higher for females. 


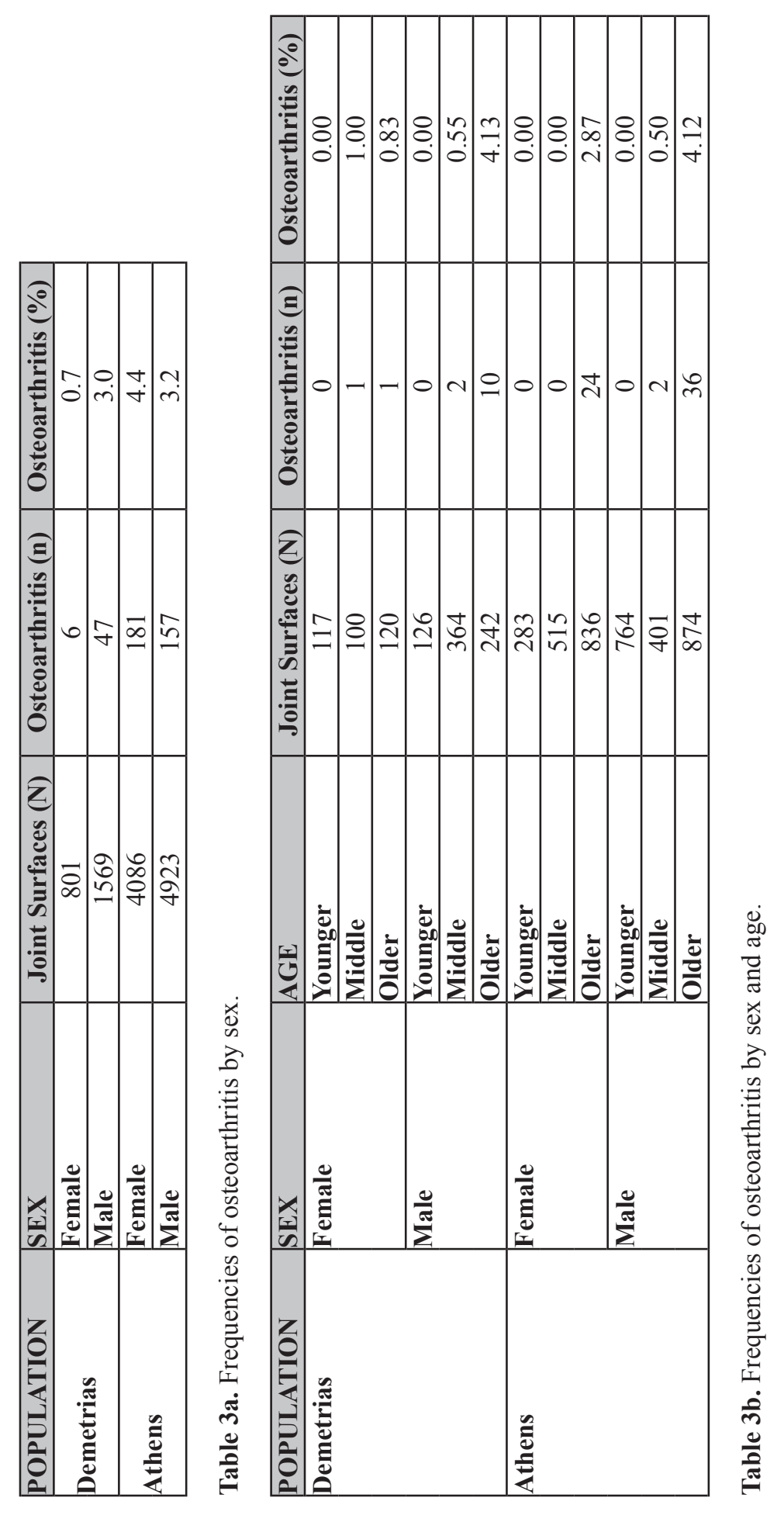




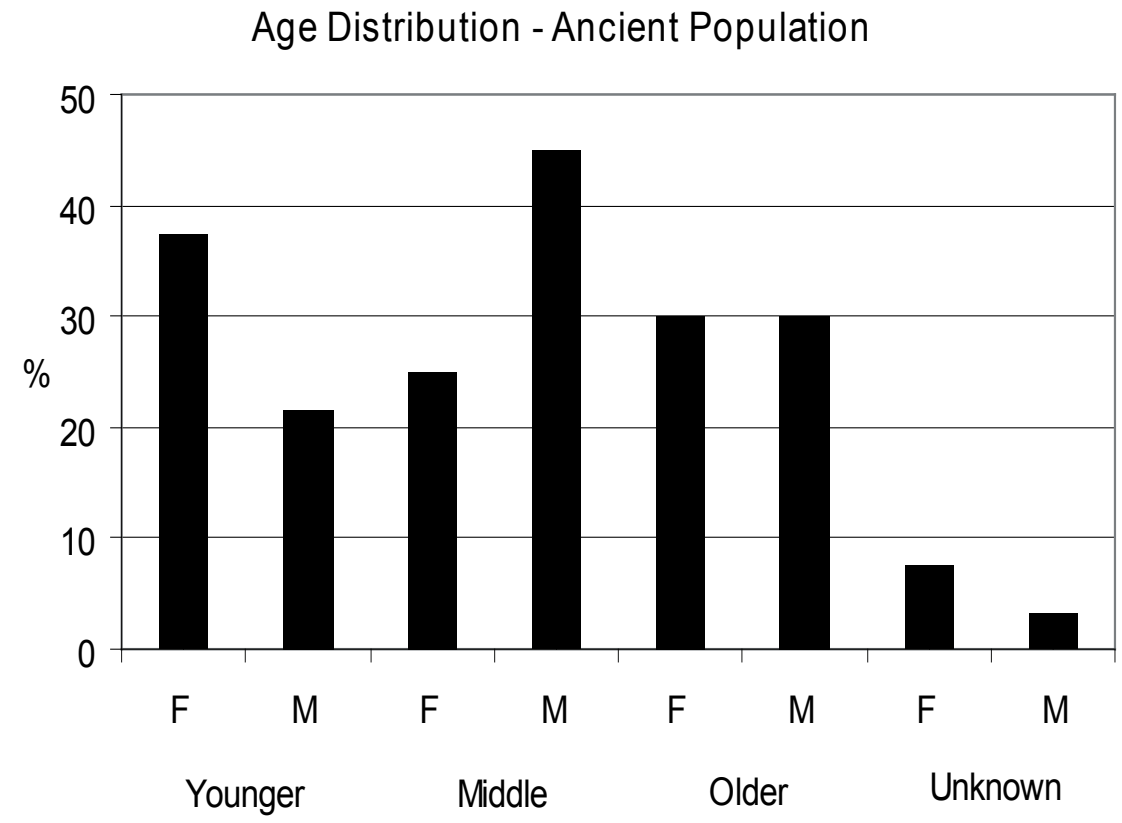

Age Distribution - Modern Population

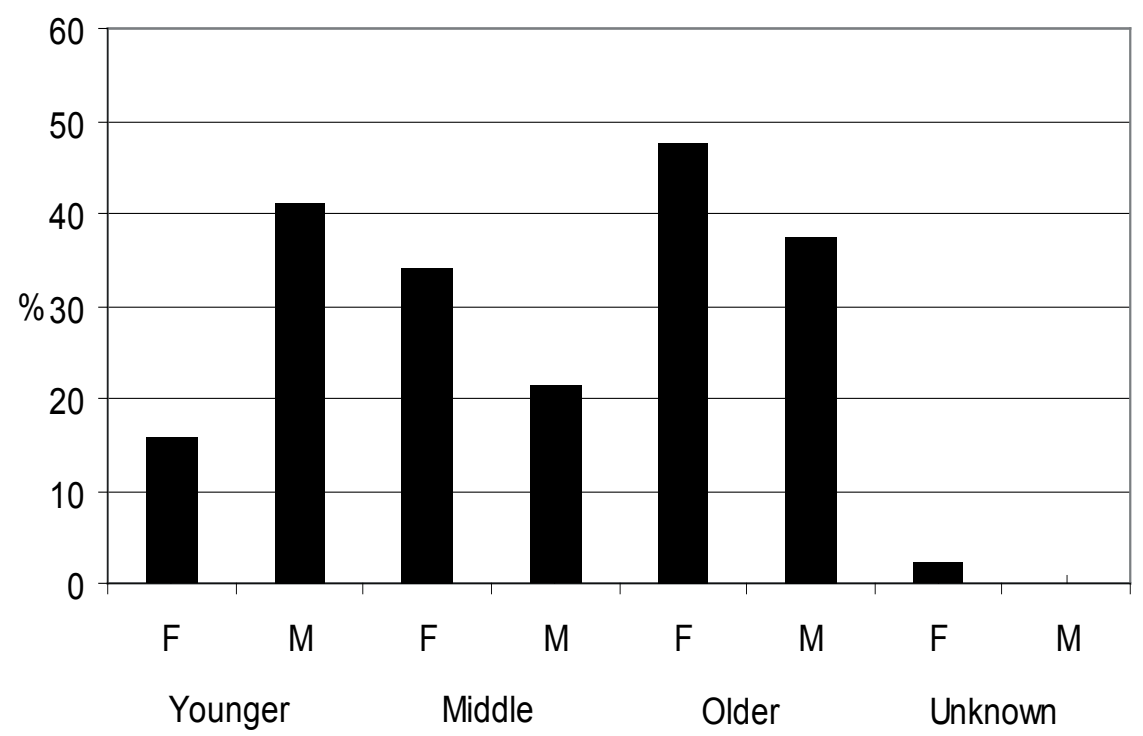

Figure 2. Mortality rates of females (F) and males $(\mathrm{M})$ in the ancient and the modern populations. Younger $=20-35$ years $/$ Middle $=35-50$ years $/$ Older $=50+$ years. 


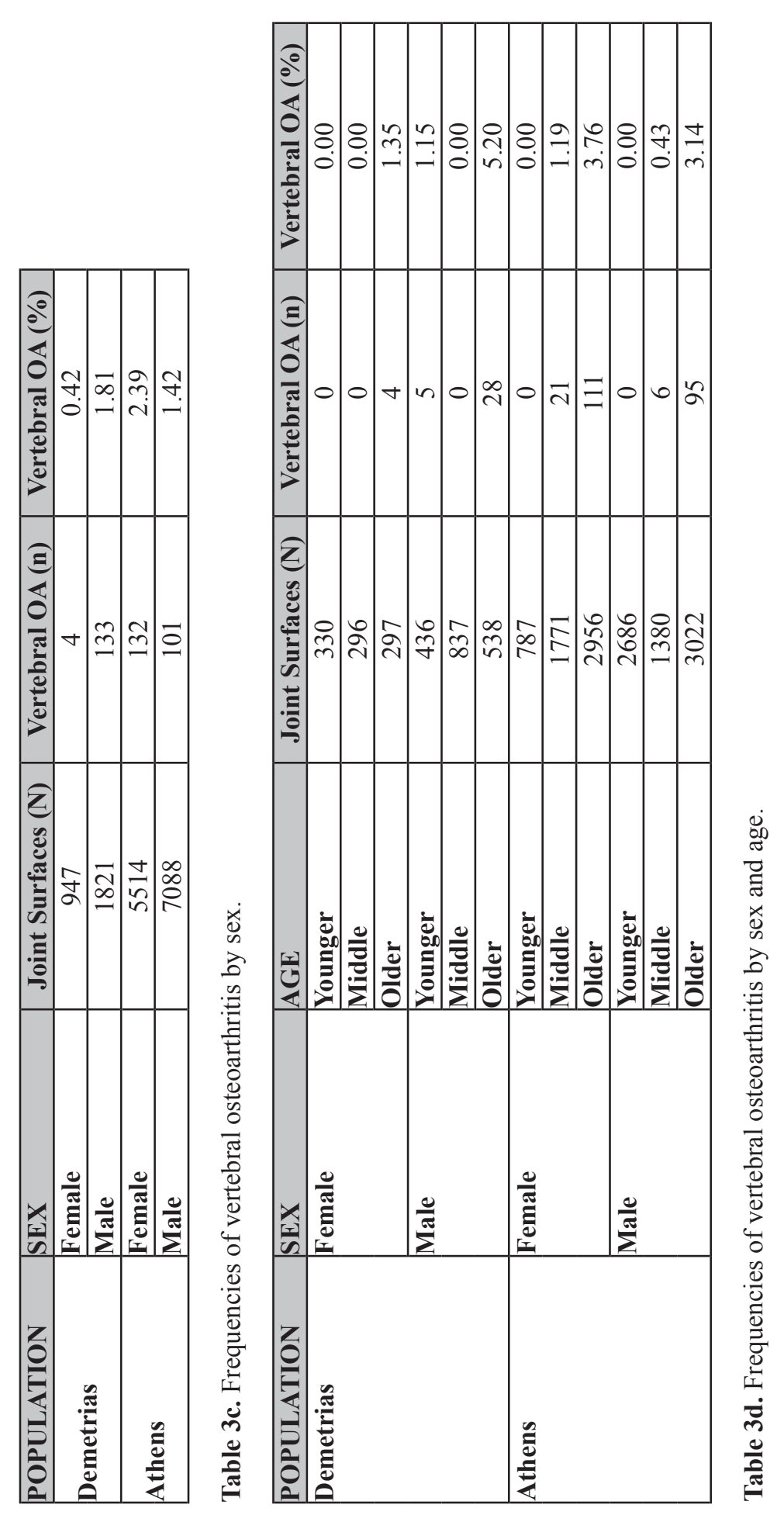




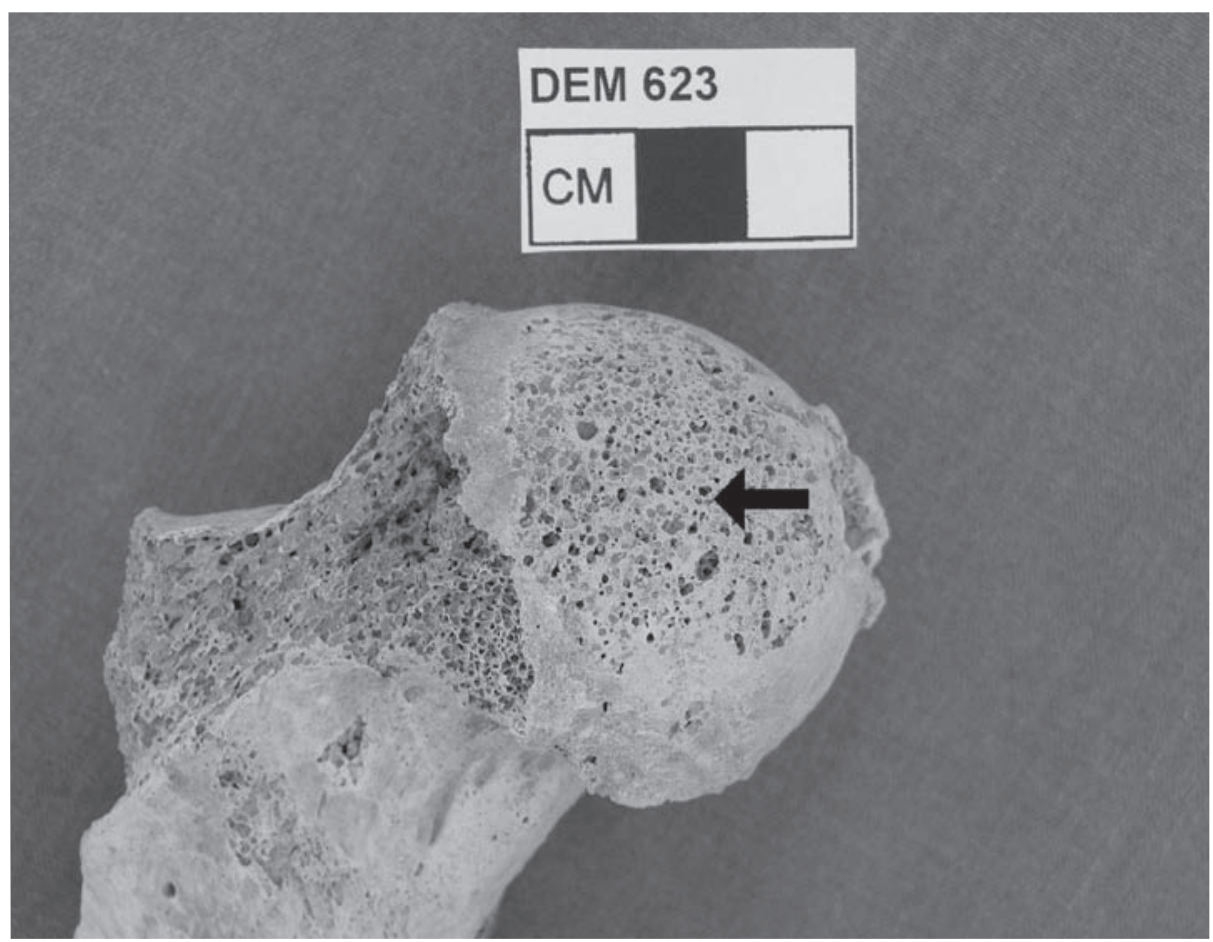

Figure 3. Osteoarthritis of the hip joint (the head of the femur is shown here); lesions: eburnation, osteophytes and pitting (example from the ancient collection).

\section{Dental Caries}

In the ancient population, males were more frequently affected by caries than females $\left(\chi^{2}=20.371, \mathrm{df}=7\right.$, Asymp. Sig. $\left.=0.005\right)$, whereas in the contemporary population, the percentage of carious teeth of female individuals was considerably higher than that of males (Table 4a, $\chi^{2}=97.122$, df=9, Asymp. Sig. $=0.000$ ). As discussed above, most populations show a higher prevalence of dental caries in females for a number of reasons. For the modern population, there is also the greater lifespan of women that contributes to the higher caries rates for females.

The difference in the overall (regardless of age) rates of caries between the sexes (males more frequently affected than females) in the ancient population could be attributed to differential access to food resources, different dietary habits, different hygiene practices, and/or age distribution, etc. When age-groups are independently compared, however, it is obvious that this overall difference between the sexes is strongly agedependent (Table 4b). In the younger age group (20-35 yrs), females showed higher rates of caries and this is explained by hormonal fluctuations, low quality saliva composition and/or flow, pregnancy and earlier eruption of female teeth. In the middle adult subgroup (35-50 yrs), the frequency is significantly higher than in male individuals but the percentage of males (45\%) that died between the ages of 35 and 50 (i.e. middle 

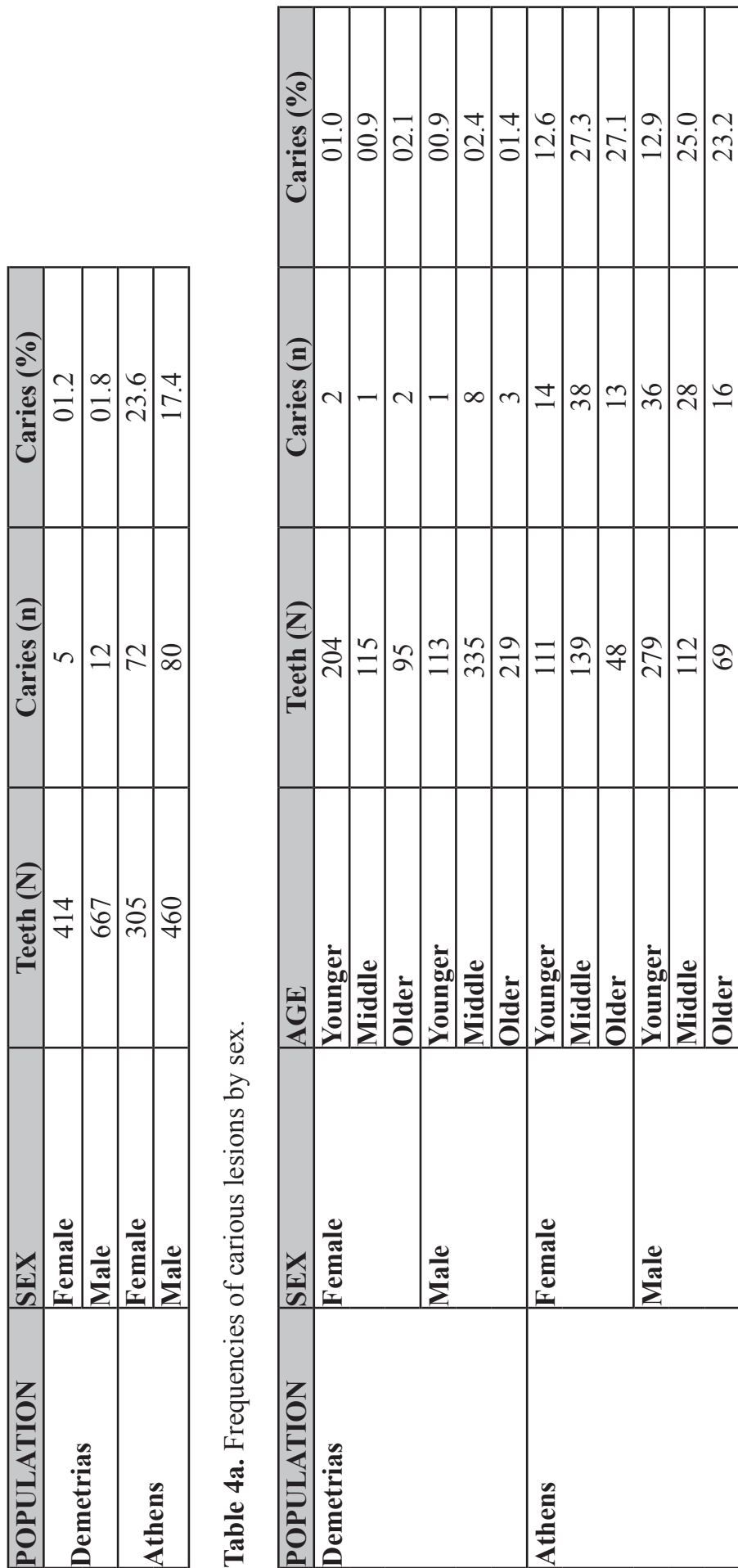

ยั

ق

Uึ:

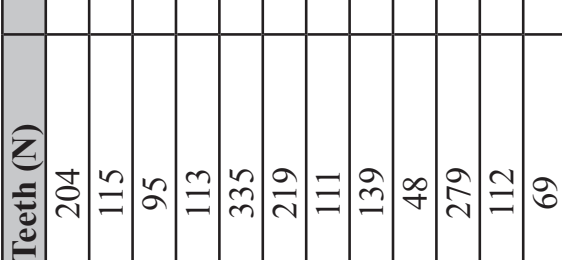

这

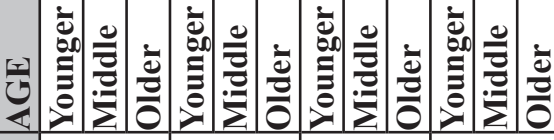

F

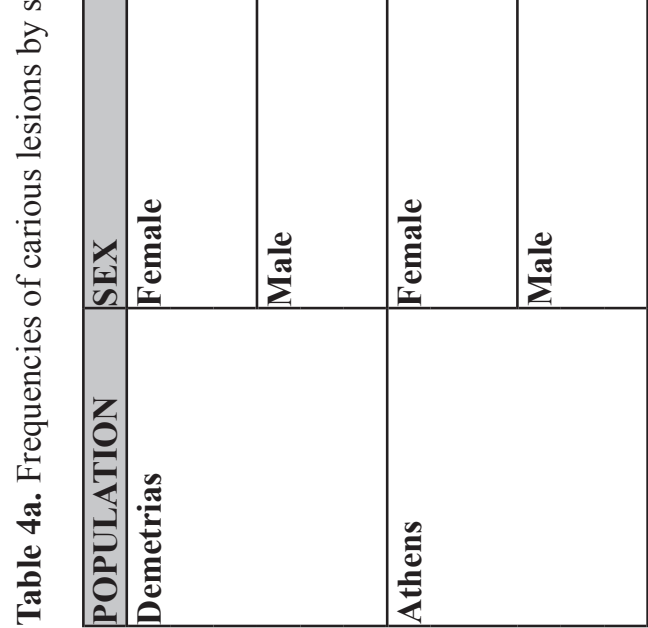

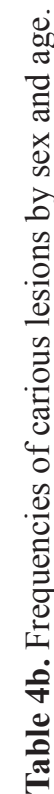


adults) is also much higher than that of females (25\%) (Fig. 2, Table 4b); therefore, this difference is is clearly affected by age. Finally, in the older adult group (50+ yrs) females were more frequently affected by dental caries than males, and since the percentage of males and females that died after the age of 50 is equal (30\%), the age-at-death does not seem to contribute to this difference. The elevated levels of carious lesions in females should first of all be attributed to hormonal fluctuations, saliva content and flow, earlier eruption of female teeth, and possibly to higher levels of carbohydrate consumption by women, and/or higher frequency of between-meal eating, all of which result in high rates of caries. Both higher consumption of carbohydrates and snacking between meals are common habits among females in many past and present societies (Larsen 1997: 74-75): firstly, this is because women consume cheaper foods than men; secondly, because they spend most of their time in the house and thirdly, they are the ones responsible for preparing the meals.

Conclusively, both the fact that males showed elevated rates of caries only in the middle adult group and that the percentage of male individuals represented in this age group was much higher (also meaning that men lived longer) than that of females, suggest that, excluding the age-factor, females were in fact more frequently affected by caries than males, which is what was expected.

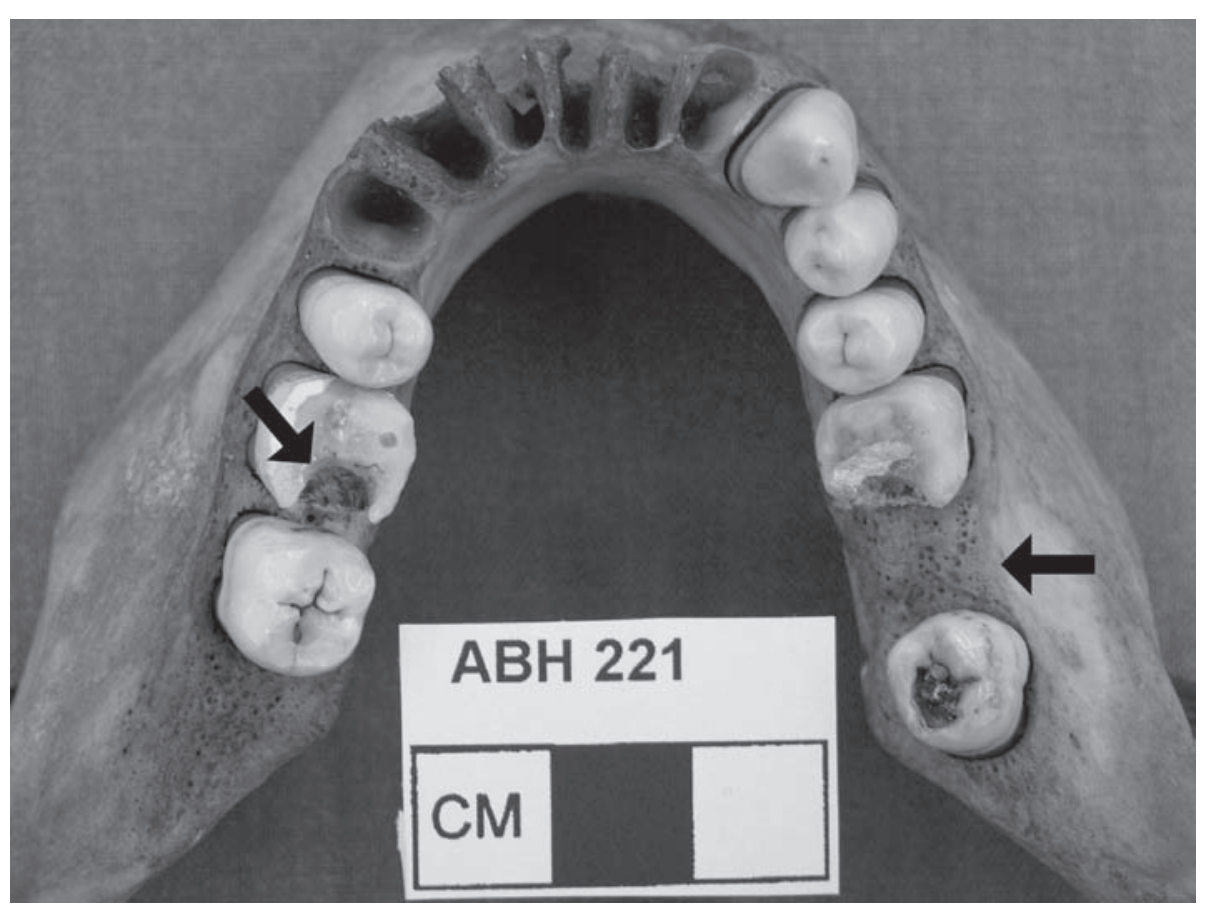

Figure 4. Dental caries, ante-mortem tooth loss and occlusal attrition (example from the modern collection). 


\section{Periodontitis and Ante-mortem Tooth Loss}

Horizontal periodontal disease, in both collections, was found to be more frequent and more severe in male individuals (Tables 5a and 5b, Demetrias: $\chi^{2}=20.028$, $\mathrm{df}=2$, Asymp. Sig. $=0.000$, Athens: $\chi^{2}=25.659, \mathrm{df}=2$, Asymp. Sig. $\left.=0.000\right)$, whereas vertical periodontitis (Demetrias: $\chi^{2}=45.419, \mathrm{df}=1$, Asymp. Sig. $=0.000$, Athens: $\chi^{2}=4.074, \mathrm{df}=1$, Asymp. Sig. $=0.044$ ) and ante-mortem tooth loss (Demetrias: $\chi^{2}=6.327, \mathrm{df}=1$, Asymp. Sig. $=0.012$, Athens: $\chi^{2}=63.157, \mathrm{df}=1$, Asymp. Sig. $=0.000$ ) showed higher rates in the females (Tables 6a, 6b, 7a, and 7b), which may seem inconsistent, since the two phenomena (periodontitis and tooth loss) are very closely related to each other. A possible explanation is given below.

\section{Occlusal Attrition}

Occlusal attrition is significantly more severe in males compared to females, perhaps suggesting consumption of tough foods and/or use of teeth for non-dietary purposes by men.

\section{Association Among Caries, Periodontitis, Ante-mortem Tooth Loss and Occlusal Attrition in the Populations Under Study}

Dental caries, vertical and horizontal periodontitis, ante-mortem tooth loss and occlusal attrition (Fig. 4) are very closely related to each other. More specifically, both caries and periodontitis, when they progress may lead to tooth loss. At a population level, there is an inverse relationship between caries frequencies and heavy occlusal attrition (Hillson 1996). It is therefore very important to determine this relation in the samples under study and interpret the distribution of each condition between the sexes, by combining the data provided by each one of them. Synoptically, in both the ancient and the modern populations, caries levels were higher for females (Table 4a), vertical periodontitis frequencies were more elevated for females (Table 6) whereas horizontal periodontitis rates were higher for male individuals (Table 5a), ante-mortem tooth loss affected females more than males (Table 7), and occlusal attrition was significantly more severe in male individuals.

Both caries and vertical and horizontal periodontal disease are conditions that very often result in ante-mortem tooth loss (Hillson 1996). In the first and second case, the tooth loss is associated with the (gross/severe) carious lesion or the vertical bone loss affecting each tooth independently, and is localised, i.e. confined to a small area (Karn et al. 1984). In the third case, tooth loss is associated with generalised infection of the alveolar bone as a whole and the tooth loss is generalised, affecting a large or the entire area (Kerr 1991). Therefore, and since females were more affected by caries and antemortem loss (Tables 4a and 7) but less affected by horizontal periodontitis than males (Table 5a), it can be argued that the tooth loss in female individuals is related more to localised (caries and vertical periodontitis) rather than generalised infection (horizontal periodontitis), whereas in males, ante-mortem loss could be largely attributed to generalised (horizontal periodontitis) infection of the alveolar bone.

More severe occlusal attrition in males of both populations, suggests that, compared to females, they probably ate tougher foods, namely meat (Organ et al. 2005), which 

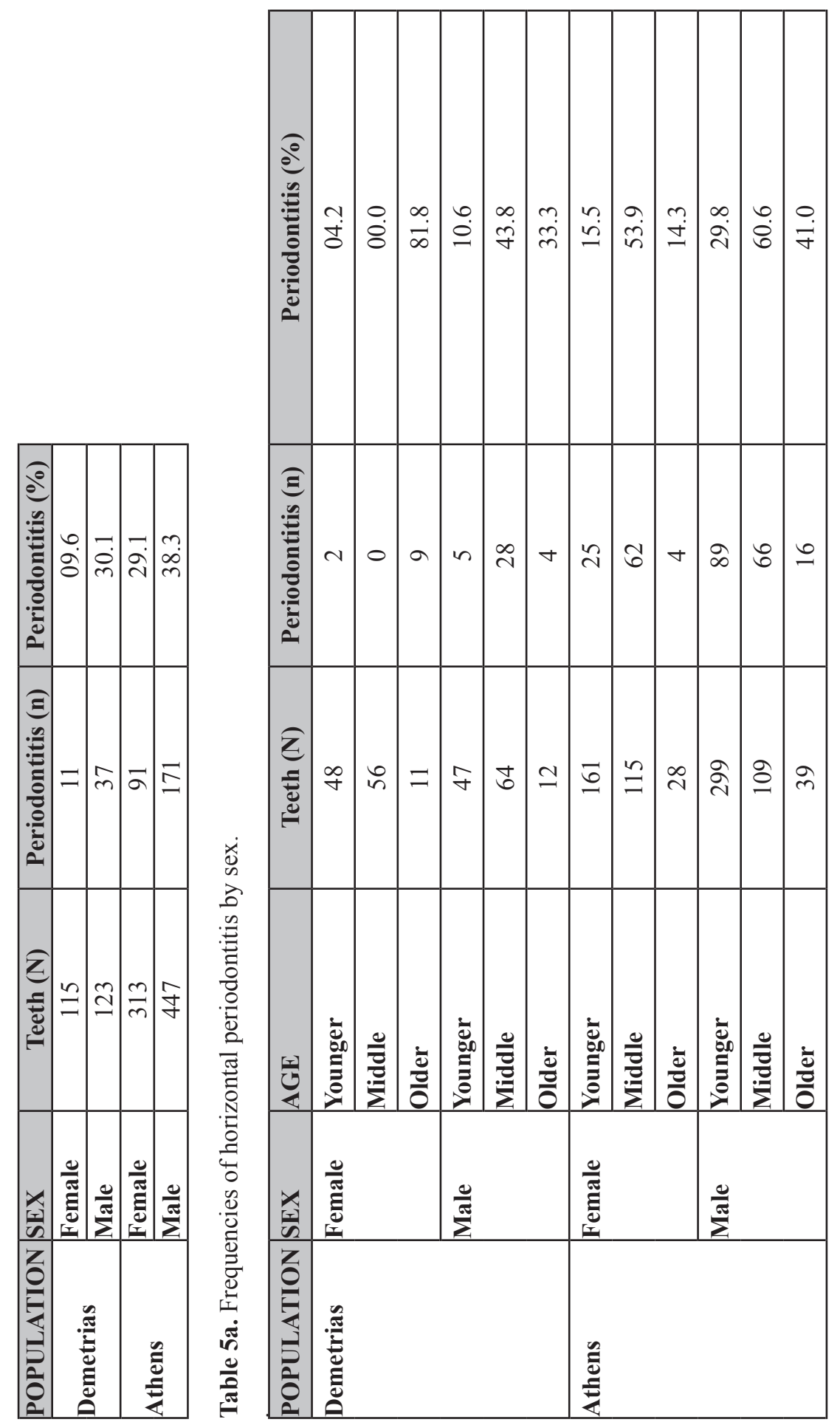

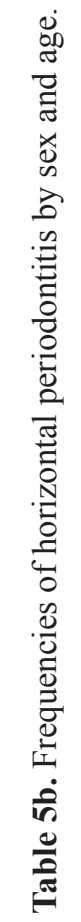


is recognised as a tough substance in that it requires a significant amount of work to cut or fracture it (Lucas and Peters 2000). That would also explain the lower rates of caries, and caries- and vertical periodontitis-associated ante-mortem tooth loss, related to higher consumption of animal protein, as opposed to a highly-cariogenic, rich-incarbohydrates female diet (Delgado-Darias et al. 2005, 2006). As in most studies, the severity of occlusal attrition is inversely-related to the frequency of carious lesions (Hall et al. 1986), firstly because softer foods are more cariogenic and secondly because unworn occlusal tooth surfaces, especially of molars that are markedly the most frequently caries-affected tooth class, concentrate more food and retain it for longer than worn surfaces (Powell 1985).

\begin{tabular}{|l|l|c|c|c|}
\hline POPULATION & SEX & Teeth (N) & Periodontitis (n) & Periodontitis (\%) \\
\hline \multirow{2}{*}{ Demetrias } & Female & 153 & 100 & 65.4 \\
\cline { 2 - 5 } & Male & 125 & 31 & 24.8 \\
\hline \multirow{2}{*}{ Athens } & Female & 427 & 84 & 19.7 \\
\cline { 2 - 5 } & Male & 276 & 38 & 13.8 \\
\hline
\end{tabular}

Table 6. Frequencies of vertical periodontitis by sex.

\begin{tabular}{|l|l|c|c|c|}
\hline POPULATION & SEX & Teeth (N) & AMTL (n) & AMTL (\%) \\
\hline \multirow{2}{*}{ Demetrias } & Female & 747 & 92 & 12.3 \\
\cline { 2 - 5 } & Male & 443 & 34 & 07.7 \\
\hline \multirow{2}{*}{ Athens } & Female & 764 & 531 & 69.5 \\
\cline { 2 - 5 } & Male & 752 & 372 & 49.5 \\
\hline
\end{tabular}

Table 7. Frequencies of antemortem tooth-loss by sex.

The fact that horizontal periodontitis frequency is higher for males (Table 5a), although caries and especially ante-mortem loss rates are lower than those for females (Tables 4a and 7), may be related to poor oral hygiene in men, leading to high levels of plaque deposits. Another possible explanation, which does not preclude the factor of poor oral hygiene practices is excessive masticatory loading of the jaws and teeth. Excessive masticatory loading is a potential irritant to the soft tissues surrounding alveolar bone, and progressively the alveolar bone itself, and is the result of the consumption of tough-textured foods (Pedersen and Jakobsen 1989). This explanation ties in with the argument that heavier occlusal attrition is associated with the consumption of tough foods, possibly meat. Thus, extreme mechanical demands results in severe wear, pulp exposure and resorption and shortening of the roots, resulting in tooth loss (Larsen 1997; Tsilivakos et al. 2002).

\section{Dental Defects of Enamel}

Population analysis using dental enamel defects (Fig. 5) as health-indicators is based on the assumption that differences in the frequency of the condition reflect differences in the stress levels of a population (Stodder 1997). However, as previously mentioned, there is a problem with the interpretation of the results given by such analysis. According to some researchers, the more frequent the defects the greater was the stress 
experienced during childhood, thus the less favourable life conditions the population or the population subgroup had (Goodman and Armelagos 1980; Malville 1997; Ubelaker 1992). Others (Arcini 1999) suggest that stress markers mean that the individual managed to get through the disease and recovered, so, his/her living conditions or individual resistance must have been better than those who had died in childhood and thereby do not show any traces of stress on their teeth. Since in skeletal studies it is impossible to know how many of the children that were born experienced stress, survived or died, "such a conflicting view remains in the interpretation of associations between enamel defects and the longevity of individuals" (Palubeckaite et al. 2002: 190).

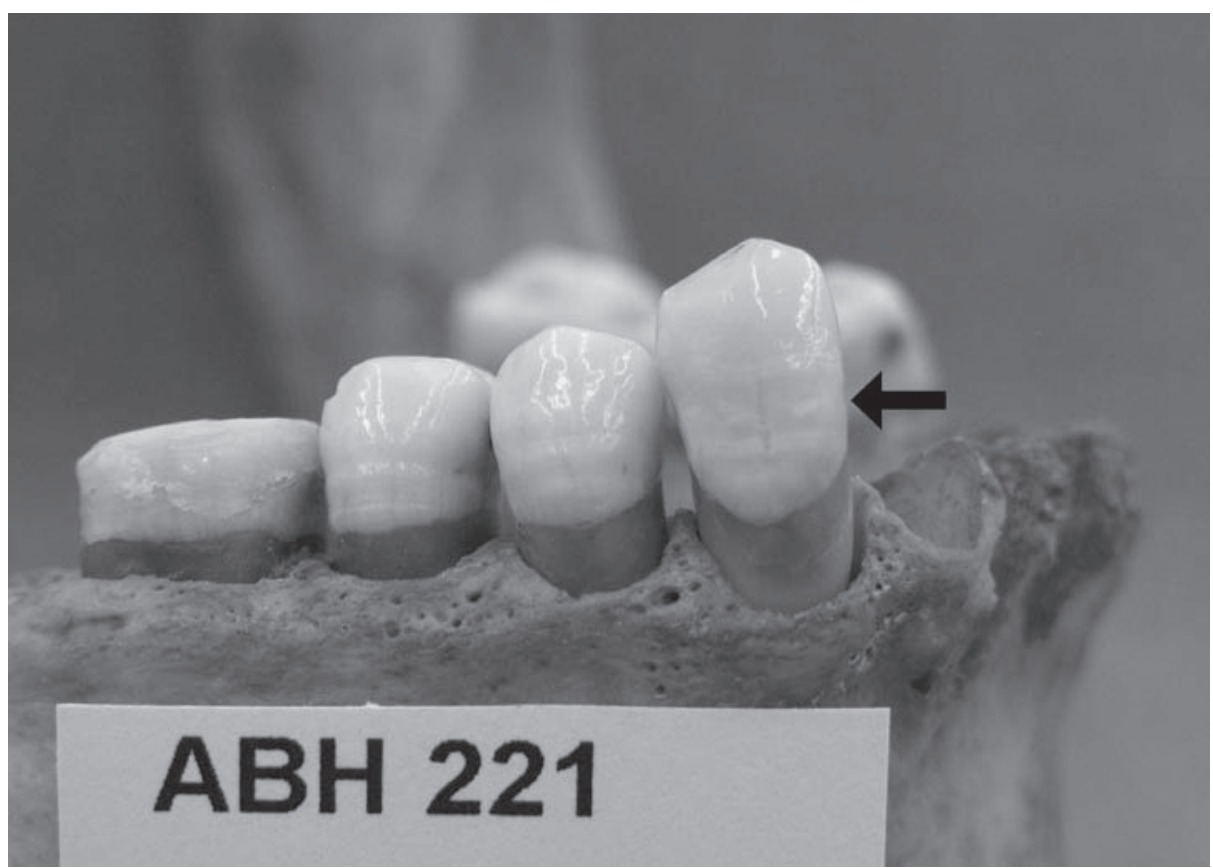

Figure 5. Dental defects of enamel (example from the modern collection).

In the ancient population under study, it was found that the individuals with the significantly higher frequency of dental enamel defects, i.e. the males (Tables $8 \mathrm{a}$ and $8 \mathrm{~b}$, $\chi^{2}=0.010, \mathrm{df}=1$, Asymp. Sig. $=0.921$ ), were those who lived longer. In the modern population, the individuals with greater lifespan, i.e. females, exhibited lower rates of dental enamel defects $\left(\chi^{2}=16.115, \mathrm{df}=1\right.$, Asymp. Sig. $\left.=0.000\right)$. Therefore, in the case of the Hellenistic population, the presence of defects equates with better life conditions and more specifically, it means that males, although they were exposed to stress during childhood, had more chances of surviving so there was time for the defects to develop as they reached adulthood. Females, on the other hand, were exposed to disease and nutritional deficiencies but there was not a time for them to develop the defects because they died shortly after at a young age and never reached adulthood. In the modern population, the exact opposite is the case: presence of enamel defects equates with worse living conditions for those, namely men, who exhibited them in higher frequencies. 

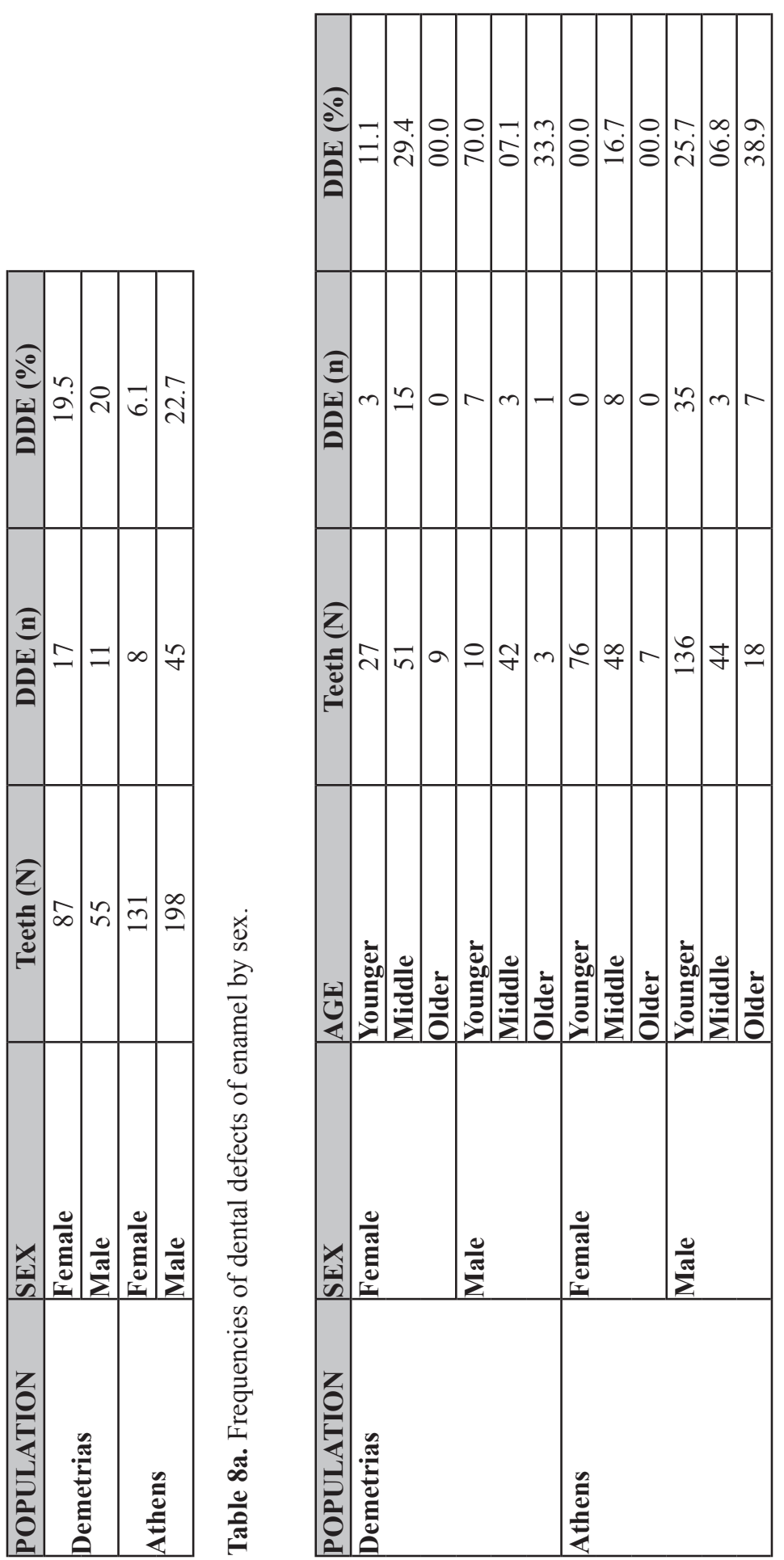

$\Xi$

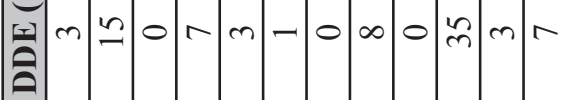

$\hat{\bar{\theta}}$

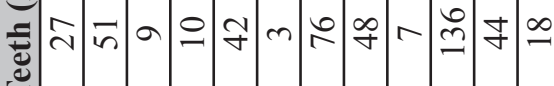

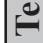

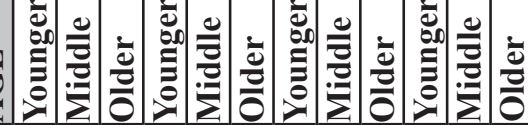

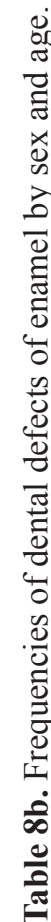


This difference may be attributed to the higher immune reactivity of women. Therefore, in the ancient population, it seems that social factors (differential treatment between males and females in childhood years, inferior nutritional value for girls) prevail over biological ones (more effective female immune response). In the modern population, on the other hand, it seems that biological factors were superseded by social factors, and women with greater resistance survived the stress and reached an older age.

\section{Conclusions}

The overall impression, when comparing the two populations, is that, although they are very distant chronologically and they have completely different backgrounds, the sex-related health differences detected in each of them are very similar. It appears that changing social conditions do not have a major influence on the distribution of osteoarthritis, fractures and dental pathology between the sexes. This could mean that: (a) social differences between men and women do not influence sex-related health status differences, (b) social differences do not have an impact on the skeleton and are therefore not reflected in the distribution of disease and trauma between the sexes in skeletal populations, or (c) the changes in certain gender-related social differences from ancient to modern times are not as dramatic as to significantly influence the distribution of disease and trauma between the sexes.

The first two explanations should be excluded because a large number of studies in both epidemiology and palaeopathology have shown that different social backgrounds lead to sometimes even major differences in the health status among and within populations (Bourbou 2004; Derevenski 2000; Judd 2004; King et al. 2005; Lezzi 2005; Palubeckaite et al. 2002; Slaus 2000; Standen and Arriaza 2000; Triantafyllou 2001) although in many cases, no statistically significant differences between the sexes have been found (Delgado-Darias et al. 2005; Pechenkina et al. 2002). The third option seems to apply here. The reason is that, although the populations under study come from totally different socio-economic backgrounds, some factors affecting the distribution of osteoarthritis, fractures and dental pathology remains stable, and these are the biological factors discussed above. In addition, although the status of women has increased in the modern times, some social factors either remain the same or have only slightly changed: women still spend more time in the house than men, who get involved in more strenuous activity than women (Standen and Arriaza 2000).

The only major difference observed between the ancient and the modern population, in terms of sex differences, was in lifespan. In the ancient population men lived longer than women, whereas in the $20^{\text {th }}$ century population women lived longer than men. This should mainly be attributed to the fact that, in the modern population, the biological factor of enhanced female immune reactivity remained stable, whereas, at the same time, two other factors, principally the enormous advances in the medical field that allowed many more women to survive during the child-bearing years, and maybe to a lesser extent, the vast male mortality rates during the wars (Balkan Wars, World War I, II, the Civil War, etc.) emerge. 
This research paper has considered male and female susceptibility to fractures, joint disease and dental pathologies and the aetiology behind it, but was also written with the purpose of highlighting the following points:

- The importance of population-based (as opposed to case-) studies in bioarchaeology, because they are the only means of answering hypotheses-driven research questions concerning lifestyle and health in past societies.

- The significance of making intra-population comparisons, because (a) age and sex distribution and the biological and social factors associated with them, strongly influence the prevalence of disease and the outcome of the study and (b) such comparisons can be used to test hypotheses and consider issues such as sex and gender differences, the association between skeletal markers and pathologies.

- The value of the use of multiple health indicators, because the prevalence and distribution in the population and the pattern in the skeleton of various pathological conditions in skeletal assemblages (a) give an overall picture of the biological status of populations or population subgroups, (b) provide information on various aspects of life history, such as activity, socio-economic status, diet, etc. and (c) help in testing hypotheses, especially when there is no archaeological or historical evidence available.

- The usefulness of sex- and gender- related differences in investigating health and of the consideration of both the biological and social factors affecting this variation.

Studies of disease prevalence in human skeletal remains that allude to the presence of gender inequality are largely products of our modern interest in gender issues. However, the reasons may lie less in gender inequality than in reproductive biology (Cook and Hunt 1998). Although it is very difficult to identify the cause of disease prevalence and distribution in osteological assemblages, the study of health status in skeletal populations in their historical and archaeological context, can substantially contribute to our understanding of past human societies.

\section{Limitations and Future Directions}

In the future, when mortuary evidence for the ancient population and the occupation of the individuals from the modern collection become available, this study can be used to further investigate the effect of social conditions and labour division on the distribution of disease between the sexes. A future direction would also be to compare the data provided by this study with that from other Hellenistic population studies, which are very few at present. It should also be noted that the data obtained by this research project provide the first direct or indirect evidence on the population's health status and on gender differences in this area of Greece in the Hellenistic period; again this makes it difficult to put it into a wider context. However, they provide a basis for future studies on the anthropology and archaeology of the region of which very little is known in terms of population biology, everyday life and social conditions. 


\section{Acknowledgements}

I would first of all like to the anonymous reviewers for their very useful comments. I would also like to express my gratitude to the UCL Institute of Archaeology and my supervisors Prof. S. Hillson and Prof. K. Thomas for their support and advice in supervising my $\mathrm{PhD}$ research on human remains. I am also grateful to $\mathrm{Dr} \mathrm{S}$. Manolis and the Laboratory of Biological Anthropology, Department of Biology, University of Athens, for permission to study the modern collection, to Mrs Elsa Nikolaou and $13^{\text {th }}$ Ephorate of Prehistoric and Classical Antiquities of Volos, Greece, for permission to study the Hellenistic collection of Demetrias, to F. Koutsoubos for his excellent guidance and for helping me with the statistical analysis and interpretation, to G. Foundoulakis for discussing with me issues related to dental disease prevalence, to C. Eliopoulos for his generous assistance in taking the photographs of the specimens, and Demetra, Giorgos, Yiannis and Christina.

\section{References}

Acsadi, G. and Nemeskeri, J. 1970. History of Human Life Span and Mortality. Budapest: Akademiai Kiado.

Alvrus, A. 1999. Fracture Patterns Among the Nubians of Semna South, Sudanese Nubia. International Journal of Osteoarchaeology 9, 417-429.

Angel, J. L. 1981. History and Development of Palaeopathology. American Journal of Physical Anthropology 56, 509-515.

Angsusingha, K., Kenny, F. M., Nankin, H. R. and Taylor, F. H. 1974. Unconjugated Estrone, Estradiol and FSH and LH in Pre-pubertal and Pubertal Males and Females. Journal of Clinical Endocrinology and Metabolism 39, 63-68.

Arcini, C. 1999. Health and Disease in Early Lund: Osteopathologic Studies of 350 Individuals Buried in the First Cemetery Area of Lund 990-1536, Department of Community Health Sciences, Medical Faculty, Lund University: Sweden.

Armelagos, J. 1998. Introduction: Sex, Gender and Health Status in Prehistoric and Contemporary Populations, in Grauer, A. L. and Stuart-Macadam, P. L. (eds.) Sex and Gender in Palaeopathological Perspective, Cambridge: Cambridge University Press, 1-10.

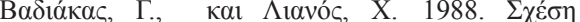

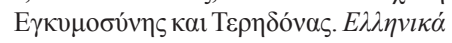

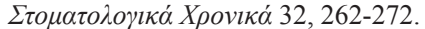

Bass, W. M. 1995. Human Osteology: A Laboratory and Field Manual ( $4^{\text {th }}$ edition). Special Publication No. 2. Columbia: Missouri Archaeological Society.

Behrend, G. A. 1978. The Epidemiology of Dental Caries and Subsistence Pattern Change. American Journal of Physical Anthropology 48, 380 .

Blundell, S. 1995. Women in Ancient Greece. Cambridge, MA: Harvard University Press.

Bourbou, C. 2004. The People in the Early Byzantine Eleutherna and Messene $\left(6^{\text {th }}-7^{\text {th }}\right.$ centuries A.D.): A Bioarchaeological Approach. Athens: University of Crete Press.

Bowman, J. E. 1991. Life History, Growth and Dental Development in Captive Rhesus Macaques. Unpublished $\mathrm{PhD}$ Thesis, University of Cambridge.

Brickley, M. 2002. An Investigation of Historical and Archaeological Evidence for Age-related Bone Loss and Osteoporosis. International Journal of Osteoarchaeology 12, 364-371. 
Bridges, P. S. 1991. Degenerative Joint Disease in Hunter-Gatherers and Agriculturalists from the Southeastern United States. American Journal of Physical Anthropology 85, 379-391.

Bridges, P. S. 1992. Prehistoric Arthritis in the Americas. Annual Review of Anthropology 21, 67-91.

Bridges, P. S. 1993. The Effect of Variation in the Methodology and the Outcome of Osteoarthritic Studies. International Journal of Osteoarchaeology 3, 289. 295.

Brooks, S. T. and Suchey, J. M. 1990. Skeletal Age Determination Based on the Os Pubis: AComparison of the Acsadi-Nemeskeri and Suchey-Brooks Methods. Human Evolution 5, 227-238.

Brothwell, D. R. 1981. Digging Up Bones. London and Oxford: British Museum and Oxford University Press

Chamberlain, A. 2000. Problems and Prospects in Palaeodemography, in Cox M., and Mays S. A. (eds). Human Osteology in Archaeology and Forensic Science. London: Greenwich Medical Media Ltd.

Clogg, R. 2002. A Concise History of Greece. Cambridge: Cambridge University Press.

Cook, D. C. and K. D. Hunt 1998. Sex Differences in Trace Elements: Status or Selfselection? in Grauer, A. L. and StuartMacadam, P. L. (eds.). Sex and Gender in Palaeopathological Perspective. Cambridge: Cambridge University Press, 64-78.

Delgado-Darias, T., Velasco-Vasquez, J., Arnay-dela-Rosa, M., Martin-Rodriguez, E., and Gonzalez-Reimers, E. 2005. Dental Caries Among the Prehispanic Population Gran Canaria. American Journal of Physical Anthropology 128, 560-568.
Delgado-Darias, T., Velasco-Vasquez, J., Arnay-dela-Rosa, M., Martin-Rodriguez, E., and Gonzalez-Reimers, E. 2006. Calculus, Periodontal Disease and Tooth Decay Among the Prehispanic Population from Gran Canaria. Journal of Archaeological Science 33, 663-670.

Derevenski, J. R. S. 2000. Sex Differences in Activity-Related Osseous Change in the Spine and the Gendered Division of Labor at Ensay and Wharram Percy, UK. American Journal of Physical Anthropology 111, 333-354.

Domett, K. M., Tayles, N. 2006. Adult Fracture Patterns in Prehistoric Thailand: A Biocultural Interpretation.International Journal of Osteoarchaeology 16, 185199.

Eliopoulos, C. 2006. The Creation of a Documented Human Skeletal Collection and the Application of Current Aging and Sexing Standards on a Greek Skeletal Population. Unpublished $\mathrm{PhD}$ Thesis, University of Sheffield.

Eliopoulos, C., Lagia, A. and Manolis, S. 2007. A Modern Documented Human Skeletal Collection From Greece. Journal of Comparative Human Biology 58, 221228.

Fahlstrom, G. 1981. The Glenohumeral Joint in Man: An Anatomic-Experimental and Archaeo-Osteological Study on Joint Function. Ossa: Supplement 1

Fantham, E. and Peet Foley, H. 1994. Women in the Classical World. Image and Text. Oxford: Oxford University Press.

Felson, D. T., Hannan, M. T. and Naimark, A. 1991. Occupational Physical Demands, Knee Bending and Knee Osteoarthritis: Results from the Framingham Study. Journal of Rheumatology 18, 15871592 
Grivetti, L. E. 2001. Mediterranean Food Patterns. The View from Antiquity, Ancient Greeks and Romans, in Matalas, A. L., Zampelas, A., Stavrinos, V. and Wolinsky, I. (eds.). The Mediterranean Diet: Constituents and Health Promotion. Florida: CRC Press.

Goodman, A. H. and Armelagos, G. J. 1980. Enamel Hypoplasias as Indicators of Stress in Three Prehistoric Populations from Illinois. Human Biology 52, 515-528.

Goodman, A. H. and Rose, J. C. 1990. Assessment of Systemic Physiological Perturbations from Dental Enamel Hypoplasias and Associated Histological Structures. Yearbook of Physical Anthropology 33, 59-110.

Goodman, A. H. and Rose, J. C. 1991. Dental Enamel Hypoplasias as Indicators of Nutritional Status, in Kelley, M. A. and Larsen, C. S. (eds.) Advances in Dental Anthropology. New York: Wiley-Liss, 279-293.

Grauer, A. L. and Roberts, C. A. 1996. Palaeoepidemiology, Healing and Possible Treatment of Trauma in the Medieval Cemetery Population of St. Helen-onthe-Walls, York, England. American Journal of Physical Anthropology 100, 531-544.

Hall, R. L., Morrow, R., Clarke, J. H. 1986. Dental Pathology of Prehistoric Residents of Oregon. American Journal of Physical Anthropology 69, 325-334.

Hanna, F. S., Wluka, A. E., Bell, R. J., Davis, S. R. and Cicuttini, F. M. 2005. Osteoarthritis and the Postmenopausal Woman: Epidemiological, Magnetic Resonance Imaging, and Radiological Findings. Seminars in Arthritis and Rheumatism 34(3), 631.

Hillson, S. 1979. Diet and Dental Disease. World Archaeology 11, 147-162.

Hillson, 1986. Teeth. Cambridge: Cambridge University Press.
Hillson, S. 1996. Dental Anthropology. Cambridge: Cambridge University Press.

Hillson, S. 2000. Dental Pathology, in Katzenberg, M. A. and Saunders, S. R. (eds.) Biological Anthropology of the Human Skeleton. New York: Wiley-Liss, 249286.

Hillson, S. 2001. Recording dental caries in archaeological human remains. International Journal of Osteoarchaeology 11, 249-289.

Hoffman, D. F. 1993. Arthritis and Exercise. Primary Care 20, 895-910.

Hooton, E. A. 1930. The Indians of Pecos Pueblo. New Haven: Yale University Press.

Iscan, M. Y., Loth, S. R. and Wright, R. K. 1984. Age Estimation from the Rib by Phase Analysis: White Males. Journal of Forensic Sciences 29, 1094-1104.

Iscan, M. Y., Loth, S. R. and Wright, R. K. 1985. Age Estimation from the Rib by Phase Analysis: White Females. Journal of Forensic Sciences 30, 853-863.

Ivanhoe, F. 1970. Was Virchow Right About Neanderthal? Nature 227, 577-579.

Judd, M. 2004. Trauma in the City of Kerma: Ancient Versus Modern Injury Patterns. International Journal of Osteoarchaeology 14, 34-51.

Judd, M. A. and Roberts, C. A. 1998. Fracture Patterns at the Medieval Leper Hospital in Chichester. American Journal of Physical Anthropology 105, 43-55.

Judd, M. A. and Roberts, C. A. 1999. Fracture Trauma in a Medieval British Farming Village. American Journal of Physical Anthropology 109, 229-243.

Jurmain, R. D. 1991. Degenerative Disease as an Indicator of Occupational Stress; Opportunities and Limitations. International Journal of Osteoarchaeology 1, 247-252. 
Jurmain, R. D. 1999. Stories from the Skeleton. London and New York: Taylor and Francis

Karn, K. W., Shockett, H. P., Moffitt, W. C. and Gray, J. L. 1984. Topographic Classification of Deformities of the Alveolar Process. Journal of Periodontology 55, 336340 .

Kelly, J. O., Angel, J. L. 1987. Life Stresses of Slavery. American Journal of Physical Anthropology 74, 199-211.

Kerr, N. W. 1991. Prevalence and Natural History of Periodontal Disease in Scotlandthe Medieval Period (900-1600 AD) Journal of Dental Research 26, 346354

King, T., Humphrey, L. T. and Hillson, S. 2005 Linear Enamel Hypoplasias as Indicators of Systemic Physiological Stress: Evidence From Two Known Age-at-Death and Sex Populations From Postmedieval London. American Journal of Physical Anthropology 128 547-559.

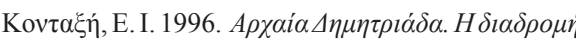

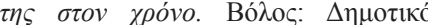

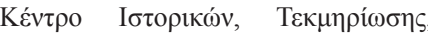

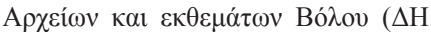
K.I).

Kreshover, S. J. 1960. Metabolic Disturbances in Tooth Formation. Annals of the New York Academy of Sciences 85, 161167.

Kujala, U. M., Kettunen, J. and Paananen, H. 1995. Knee Osteoarthritis in Former Runners, Soccer Players, Weight Lifters, and Shooters. Arthritis and Rheumatism 38, 539-546.

Lawrence, J. S. 1955. Rheumatism in Coal Miners. Part III: Occupational Factors. British Journal of Industrial Medicine 12 249-261.
Lawrence, J. S., Bremmer, J. M., Bier, F. 1966. Os teoarthrosis. Prevalence in the Population and Relationship between Symptoms and X-ray Changes. Annals of the Rheumatic Diseases 25, 1-24.

Lawrence, J. S. 1969. Generalized Osteoarthrosis in a Population Sample. American Journal of Epidemiology 90, 381-389.

Larsen, C. S. 1982. The Anthropology of St. Catherine's Island: 3. Prehistoric Human Adaptation. Anthropological Papers of the American Museum of Natural History 57.

Larsen, C. S. 1983. Behavioral Implications of Temporal Change in Cariogenesis. Journal of Archaeological Science 10, 1-8.

Larsen, C. S. 1997. Bioarchaeology. Interpreting Behavior from the Human Skeleton. Cambridge: Cambridge University Press.

Legler, D. W. and Menaker, L. 1980. Definition, Etiology, Epidemiology and Clinical Implication of Dental Caries, in Menaker, L. (ed.) The Biological Basis of Dental Caries. New York: Harper and Row, 217.

Lezzi, C. A. 2005. Regional Differences in the Health Status of Late Bronze Age Mycenean Populations from East Lokris, Greece. Unpublished PhD Thesis, University of New York at Buffalo.

Lingstrom, P. Moynihan, P. 2003. Nutrition, Saliva, and Oral Health. Nutrition 19, 753757.

Liu, F. T. Y. and Lin, H. S. 1973. Effect of Contraceptive Steroids Norethynodrel and Menstranol on Dental Caries: Activity in Young Adult Female Rats. Journal of Dental Research 52: 753-757.

Lovejoy, C. O. and Heiple, K. G. 1981. The Analysis of Fractures in Skeletal Populations with an Example from the Libben Site, Ottowa County, Ohio. American Journal of Physical Anthropology 55, 529541. 
Lovejoy, C. O., Meindl, R. S., Pryzbeck, R. T. and Mensfroth, R. P. 1985. Chronological Metamorphosis of the Auricular Surface of the Ilium: A New Method for the Determination of Age at Death. American Journal of Physical Anthropology 68, 15-28.

Lovell, N. C. 1997. Trauma Analysis in Palaeopathology. Yearbook of Physical Anthropology 40, 139-170.

Lovell, N. C. Whyte, I. 1999. Patterns of Dental Enamel Defects at Ancient Mendes, Egypt. American Journal of Physical Anthropology 110, 69-80.

Lucas, P. W. and Peters, C. R. 2000. Function of Postcanine Tooth Shape in Mammals, in Teaford, M. F., Smith, M. M. and Ferguson, M. W. J.(eds.). Development, Function and Evolution of Teeth. New York: Cambridge University Press, 282-289.

Lukacs, J. R. 1989. Dental Palaeopathology: Methods for Reconstructing Dietary Patterns, in Iscan, M. Y. and Kennedy, K. A. R. (eds.) Reconstruction of Life from the Skeleton. New York: Alan R. Liss, 261-286.

Lukacs, J. R. 1992. Dental Palaeopathology and Agricultural Intensification in South Asia: New Evidence from Bronze Age Harappa. American Journal of Physical Anthropology, 86, 133-150.

Lukacs, J. R. and Largaespada, L. L. 2006. Explaining Sex Differences in Dental Caries Prevalence: Saliva, Hormones, and "Life-History" Etiologies. American Journal of Human Biology $18,540-555$.

Malville, N. J. 1997. Enamel Hypoplasia in Ancestral Puebloan Population from Southwestern Colorado: I. Permanent Dentition. American Journal of Physical Anthropology 102, 351-367.

Mays, S., Turner-Walker, G., Syversen, U. 2006. Osteoporosis in a Population From Medieval Norway. American Journal of Physical Anthropology 131, 343-351.
Meidl, R. S. and Lovejoy, C. O. 1985. Ectocranial Suture Closure: A Revised Method for the Determination of Skeletal Age at Death Based on the Lateral-Anterior Suture. American Journal of Physical Anthropology 68, 57-66.

Meidl, R. S. and Lovejoy, C. O. 1989. Age Changes in the Pelvis: Implications for Palaeodemography, in Iscan, M. Y. (ed.) Age Markers in the Human Skeleton. Springfield, Illionois: Charles. C. Thomas, 137-168.

Merbs, C. F. 1996 . Spondylolys is and Spondylolysthesis: A Cost of Being an Erect Biped or a Clever Adaptation? Yearbook of Physical Anthropology 39, 201-228.

Merbs, C. F. 2001 Degenerative Spondylolisthesis in Ancient and Historic Skeletons from New Mexico Pueblo Sites. American Journal of Physical Anthropology 116, 285-295.

Merbs, C. F. 2002a. Asymmetrical Spondylolysis. American Journal of Physical Anthropology 119, 156-174.

Merbs, C. F. 2002b. Spondylolysis in Inuit Skeletons from Arctic Canada. International Journal of Osteoarchaeology 12, 279290.

Miles, A. E. W. 1962. Assessment of the Ages of a Population of Anglo-Saxons from their Dentitions. Proceedings of the Royal Society of Medicine 55, 881-886.

Moskowitz, R. W. 1993. Clinical and Laboratory Findings in Osteoarthritis in McCarty D. J., Coopman W. J. (eds.) Arthritis and Allied Conditions. Philadelphia: Lea and Febinger, 1735-1760.

Muhler, J. D. and Shafer, E. D. 1955. Experimental Dental Caries VII. Journal of Dental Research 34, 661-665. 
Niswender, G. D., Abulfatah, M. A. and Nett, T. M. 1976. Radioimmunoassay Procedures for Qualification of Steroid Hormones, in Antoniades, H. N. (ed.) Hormones in Human Blood: Detection and Assay. Cambridge, MA: Harvard University Press, 751-776.

Organ, J. M., Teaford, M. F., Larsen, C. S. 2005. Dietary Inferences From Dental Occlusal Microwear at Mission San Luis de Apalachee. American Journal of Physical Anthropology 128, 801-811.

Ortner, D. J. 1998. Male-Female Immune Reactivity and Its Implications for Interpreting Evidence in Human Skeletal Palaeopathology, in Grauer, A. L., Stuart-Macadam, P. L. (eds.) Sex and Gender in Palaeopathological Perspective. Cambridge: Cambridge University Press, 79-92.

Palubeckaite, Z., Jankauskas, R. and Boldsen, J. 2002. Enamel Hypoplasia in Danish and Lithuanian Late Medieval/Early Modern Samples: A Possible Reflection of Child Morbidity and Mortality Patterns. International Journal of Osteoarchaeology 12, 189-201.

Pechenkina, E. A., Benfer, R. A., Zhijun, W. 2002. Diet and Health Changes at the End of the Chinese Neolithic: The Yangshao/ Longshan Transition in Shaanxi Province. American Journal of Physical Anthropology 117, 15-36.

Pedersen, P. O, and J. Jakobsen 1989. Teeth and Jaws of the Qilakitsoq Mummies, in Hansen, J. P. H. and Gullov, C. (eds.) Eskimos in the 15th Century. Meddelelser om Gronland: Man \& Society, $112-130$.

Percival, R.S., Challacombe, S.J. and Marsh, P.D. 1994. Flow Rates of Resting Whole and Stimulated Parotid Saliva in Relation to Age and Gender. Journal of Dental Research 73, 1416-1420.

Phenice, T. W. 1969. A Newly Developed Visual Method of Sexing the Os Pubis. American Journal of Physical Anthropology 30, 297-301.
Pindborg, J. J. 1982. Aetiology of Developmenta Defects not Related to Fluorosis. International Dental Journal 32, 123 134.

Powell, M. L. 1985. The Analysis of Dental Wear and Caries for Dietary Reconstruction, in Gilbert, R. I. J. and Mielke, J. H. (eds.) The Analysis of Prehistoric Diets. Orlando: Academic Press, 307 338

Relethford, J. 2006. The Human Species: An Introduction to BiologicalAnthropology (6th edition). London: McGraw-Hill.

Richette, P., Corvol, M., Bardin, T. 2003. Estrogens, Cartilage, and Osteoarthritis. Joint Bone Spine 70(4), 257-262.

Roberts, C. A., Lewis, M. E. and Boocock, P. 1998 Infectious Disease, Sex, and Gender: the Complexity of it All, in Grauer, A. L. and Stuart-Macadam, P. L. (eds.) Sex and Gender in Palaeopathological Perspective. Cambridge: Cambridge University Press, 93-113.

Rogers, J. and Waldron, T. 1995. A Field Guide to Joint Disease in Archaeology. Chichester: John Wiley \& Sons.

Salkind, N. J. 2000. Statistics for People Who (Think They) Hate Statistics. Thousand Oaks: Sage Publications Inc.

Seidel, J. C. 1995. Activity-Induced Dental and Osseous Conditions and the Division of Activity by Gender of the Protohistoric Seneca. Unpublished $\mathrm{PhD}$ Thesis, University of Connecticut, Storrs.

Shafer, E. D. and Muhler, J. D. 1954. Experimenta Dental Caries III. Journal of Dental Research 33, 842-848.

Slaus, M. 2000. Biocultural Analysis of Sex Differences in Mortality Profiles and Stress Levels in the Late Medieval Population from Nova Raca, Croatia. American Journal of Physical Anthropology 111, 193-209. 
Smith, B. H. 1984. Patterns of Molar Wear in Hunter-Gatherers and Agriculturalists. American Journal of Physical Anthropology 63, 39-56.

Standen V. G. and Arriaza, B. T. 2000. Trauma in the Preceramic Coastal Populations of Northern Chile: Violence or Occupational Hazards? American Journal of Physical Anthropology 112, 239-249.

Stenlund, B. 1993. Shoulder Tendinitis and Osteoarthrosis of the Acromioclavicular Joint and Their Relation to Sports. British Journal of Sports Medicine 27, 125-130.

Stewart, T. D. 1958. Stone-Age Skull Surgery, a General Review with Emphasis on the New World. Smithsonian Institution Annual Report 1957, 469-491

Stini, W. A. 1990. "Osteoporosis": Etiologies, Prevention, and Treatment. Yearbook of Physical Anthropology 33, 151-194.

Stodder, A. L. W. 1997. Subadult Stress, Morbidity, and Longevity in Late Period Populations on Guam, Mariana Islands. American Journal of Physical Anthropology 104, 363-380

Suchey, J. M. and Katz, D. 1986. Skeletal Age Standards Derived from an Extensive Multiracial Sample of Modern Americans. American Journal of Physical Anthropology 69, 269.

Suckling, G., Elliot, D. C. and Thurley, D. C. 1983. The Production of Developmental Defects of the Enamel in the Incisor Teeth of Penned Sheep Resulting from Induced Parasitism. Archives of Oral Biology 28, 393-399.

Suckling, G., Elliot, D. C. and Thurley, D. C. 1986. The Macroscopic Appearance and Associated Histological Changes in the Enamel Organ of Hypoplastic Lesions of Sheep Incisor Teeth Resulting from Induced Parasitism. Archives of Oral Biology 31, 427-439.
Tenovuo, J. 1997. Salivary Parameters of Relevance for Assessing Caries Activity in Indiv iduals and Populations. Community of Dental Oral Epidemiology 25, 82-86.

Tenovuo, J. 1998. Antimicrobial Function of Human Saliva: How Important Is It for Oral Health? Acta Odontologica Scandinavica 250-256.

Triantafyllou, S. 2001. A Bioarchaeological Approach to Prehistoric Cemetery Populations from Central and Western Greek Macedonia. Oxford: BAR International Series 976.

Tsilivakos, M. G., Manolis, S. K., Vikatou, O. and Papagrigorakis, M. J. 2002. Periodontal Disease in the Mycenean (14501150 BC) Population of Aghia Triada, W. Peloponnese, Greece. International Journal of Anthropology 17, 91-100.

Ubelaker, D. H. 1992. Enamel Hypoplasia in Ancient Ecuador in: Recent Contributions to the Study of Enamel Developmental Defects. Journal of Palaeopathology. Monographic Publication 2, 207-217.

Vanna, V. 2005. Biological Status Differences Between a Hellenistic and a Modern Skeletal Population from Greece. Papers from the Institute of Archaeology 16, 90-94.

Vingard, E., Alfredsson, L. and Goldie, I. 1991. Occupation and Osteoarthrosis of the Hip and Knee: A Register-Based Cohort Study. International Journal of Epidemiology 20, 1025-1031.

Weiss, E. and Jurmain, R. 2007. Osteorthritis Revisited: A Contemporary Review of Aetiology. International Journal of Osteorchaeology 17, 437-450.

Wells, C. 1964. Bones, Bodies and Disease. Ancient Peoples and Places, Vol 37. New York: Praeger. 
Wluka, A. E., Davis, S. R., Bailey, M., Stuckey S. L. and Cicuttini, M. 2001. Users of Oestrogen Replacement Therapy Have More Knee Cartilage Than Non-Users. Annals of the Rheumatic Diseases 60 (4), 332-336.

Wood, J. W. and G. R. Milner. 1992. The Osteological Paradox. Problems of Inferring Health from Skeletal Samples. Current Anthropology 33(4), 343-370.
Worthman, C. 1995. Hormones, Sex, and Gender. Annual Review of Anthropology 24, 596-616.

Zar, J. H. 1999. Biostatistical Analysis. Upper Saddle River, New Jersey: Prentice Hall. 